Article

\title{
A DFT Screening of M-HKUST-1 MOFs for Nitrogen-Containing Compounds Adsorption
}

\author{
Shibiao Zong ${ }^{1}$, Yajing Zhang ${ }^{1}$, Na Lu ${ }^{1}$, Pan Ma ${ }^{1}$, Jianguo Wang ${ }^{2}$ and Xue-Rong Shi ${ }^{1,3, *}$ \\ 1 School of Material Engineering, Shanghai University of Engineering Science, 333 Longteng Road, \\ Songjiang District, Shanghai 201620, China; M050117110@sues.edu.cn (S.Z.); 17854311163@163.com (Y.Z.); \\ 05160003@sues.edu.cn (N.L.); mapan@sues.edu.cn (P.M.) \\ 2 State Key Laboratory of Coal Conversion, Institute of Coal Chemistry, Chinese Academy of Sciences, \\ P.O. Box 165, Taiyuan 030001, China; jgwang@sxicc.ac.cn \\ 3 Institute of Physical Chemistry, University of Innsbruck, Innrain 80-82, A-6020 Innsbruck, Austria \\ * Correspondence: shixuer05@mails.ucas.ac.cn; Tel.: +86-21-6779-1380
}

Received: 23 October 2018; Accepted: 16 November 2018; Published: 20 November 2018

\begin{abstract}
To develop promising adsorbent candidates for adsorptive denitrogenation, we screened the adsorption of $\mathrm{NO}, \mathrm{NO}_{2}$, and $\mathrm{NH}_{3}$ in 19 M-HKUST-1 $\mathrm{M}=\mathrm{Be}, \mathrm{Fe}, \mathrm{Ni}, \mathrm{Cr}, \mathrm{Co}, \mathrm{Cu}, \mathrm{V}, \mathrm{Zn}, \mathrm{Mo}, \mathrm{Mn}, \mathrm{W}, \mathrm{Sn}$, $\mathrm{Ti}, \mathrm{Cd}, \mathrm{Mg}$, Sc, Ca, Sr, and $\mathrm{Ba}$ ) systematically using first-principle calculations. Of these, four variants of M-HKUST-1 ( $\mathrm{M}=\mathrm{Ni}, \mathrm{Co}, \mathrm{V}$, and Sc) yield more negative adsorption Gibbs free energy $\Delta \mathrm{G}_{\mathrm{ads}}$ than the original Cu-HKUST-1 for three adsorbates, suggesting stronger adsorbate binding. Ti-HKUST-1, Sc-HKUST-1, and Be-HKUST- 1 are predicted to have the largest $\mathrm{NO}, \mathrm{NO}_{2}$, and $\mathrm{NH}_{3}$ adsorption energies within the screened M-HKUST-1 series, respectively. With the one exception of $\mathrm{NO}_{2}$ dissociation on V-HKUST-1, dissociative adsorption of $\mathrm{NO}, \mathrm{NO}_{2}$, and $\mathrm{NH}_{3}$ molecules on the other considered M-HKUST-1 is energetically less favorable than molecular adsorption thermodynamically. The barrier calculations show that the dissociation is difficult to occur on Cu-HKUST-1 kinetically due to the very large dissociation barrier. Electronic analysis is provided to explain the bond nature between the adsorbates and M-HKUST-1. Note that the isostructural substitution of $\mathrm{Cu}$ to the other metals is a major simplification of the system, representing the ideal situation; however, the present study provides interesting targets for experimental synthesis and testing.
\end{abstract}

Keywords: HKUST-1; metal substitution; density functional theory calculations; molecular adsorption; dissociation; nitrogen-containing compounds

\section{Introduction}

To develop efficient denitrogenation techniques is extremely important due to the detrimental effects of nitrogen-containing compounds (NCCs) on the human health and environment [1,2].

Among various denitrogenation techniques, adsorptive denitrogenation (ADN) is preferred because of its mild operating conditions. The ADN performance strongly depends on the adsorbent. Compared with traditional adsorbents such as activated carbon, metal organic frameworks (MOFs), a new type of adsorbent with metal-oxide units and organic linkers, have recently attracted attention as a promising adsorbent for nitrogen removal due to their structural flexibility and high sorption capacities [3,4].

Among the hundreds of possible MOFs, HKUST-1 is one of the most investigated in recent years. HKUST-1, also known as $\mathrm{Cu}_{3} \mathrm{BTC}_{2}$ or MOF-199, (BTC $=1,3,5$ benzene tricarboxylate) has been applied for various purposes: catalysis [5], membranes [6,7], wastewater treatment [8,9], and capturing a wide variety of gases [10]. The gravimetric density of under-coordinated "open-metal" sites in HKUST-1are regarded as the main reaction sites for molecule adsorption [11-13]. Xiao et al. [13] found that the 
NO adsorption capacity of HKUST-1 is as high as $9 \mathrm{mmol} \mathrm{g}^{-1}$ at $196 \mathrm{~K}$ and 1 bar pressure, which is higher than that of the previously reported porous materials. Infrared spectroscopy experiments show that NO is adsorbed on the coordinatively unsaturated $\mathrm{Cu}$ site of HKUST-1. Levasseur et al. [14] prepared GO (graphite oxide) and HKUST-1 composites and conducted $\mathrm{NO}_{2}$ adsorption studies under dry and humid conditions. Their results showed that compared with a single adsorbent, only under dry conditions, the composite adsorbent increased the adsorption capacity of $\mathrm{NO}_{2}$ significantly. The researchers therefore speculated that in humid conditions, $\mathrm{H}_{2} \mathrm{O}$ formed a competitive adsorption with $\mathrm{NO}_{2}$ and thus reduced the amount of $\mathrm{NO}_{2}$ adsorption. Hinks et al. [3] obtained high storage capacity for NO using different materials: HKUST-1, MOF-74 (Ni, Co), and MIL-53 (Al, Cr). The adsorption ability followed the sequence: Ni-MOF-74 > Co-MOF-74 > HKUST-1 > Cr-MIL-53 $>$ Al-MIL-53 under the same conditions. Borfecchia et al. [15] studied the interaction of $\mathrm{NH}_{3}$ with HKUST- 1 by a multitude of characterization techniques. They found $\mathrm{NH}_{3}$ chemisorbed on the $\mathrm{Cu}$ site under the dry condition and induced the distortion framework, however, retained the crystallinity of the material [15]. According to previous research [8,12-15], it can be found that HKUST-1 exhibits excellent performance in adsorbing three kinds of $\mathrm{NCCs}\left(\mathrm{NO}, \mathrm{NO}_{2}\right.$, and $\left.\mathrm{NH}_{3}\right)$ and preferentially adsorbed sites are the coordinatively unsaturated metal sites.

Besides the high $\mathrm{NO} / \mathrm{NO}_{2} / \mathrm{NH}_{3}$ capacity, recent studies show that the isostructural metal-substituted variants of HKUST-1 can be obtained by an isoform of HKUST-1 with other metals formally in place of copper. For example, recent studies have reported the synthesis of isostructural Cr [16], Ni [17], Zn [18], and Mo-substituted [19] variants of the original Cu-HKUST-1.

Based on the above discussion, HKUST- 1 with open metal centers has great potential for metal substitution and in the application for ADN. Despite the extensive experimental studies on the adsorption performance of NCCs on HKUST-1, only a few theoretical researches have focused on NCCs' adsorption behavior in MOFs. A lot of theoretical work has studied the adsorption in various MOFs of small molecules such as $\mathrm{CO}_{2}$ [20-22], $\mathrm{SO}_{2}$ [23,24], dibenzothiophene [25], $\mathrm{CH}_{4}$ [21,26,27], $\mathrm{N}_{2}$ [21], $\mathrm{N}_{2} \mathrm{O}$ [28], $\mathrm{H}_{2}$ [21], and noble gas [29]. To our best knowledge, a systematic study on the adsorption of three NCCs $\left(\mathrm{NO}, \mathrm{NO}_{2}\right.$, and $\left.\mathrm{NH}_{3}\right)$ on 19 metal-substituted variants of HKUST-1 is still missing.

In the work, we focus on the adsorption performance of $\mathrm{NCC}$, including $\mathrm{NO}, \mathrm{NO}_{2}$, and $\mathrm{NH}_{3}$, on M-HKUST-1 to investigate the effect of the metal center on the adsorption performance of NCCs on HKUST-1. We screened 19 variants of M-HKUST-1 (M = Be, Fe, Ni, Cr, Co, Cu, V, Zn, Mo, Mn, W, Sn, $\mathrm{Ti}, \mathrm{Cd}, \mathrm{Mg}, \mathrm{Sc}, \mathrm{Ca}, \mathrm{Sr}$, and $\mathrm{Ba}$ ). The objective of this work is to screen out the high-performance ADN material from various M-HKUST-1.

\section{Materials and Methods}

HKUST-1 (also known as MOF-199) exhibits a simple cubic structure, containing the $\mathrm{Cu}$ (II) paddlewheel units which are linked by 1,3,5-benzene tricarboxylate [30] (Figure S1a). To reduce the computational cost, the 156 atom, rhombohedral, primitive cell of HKUST-1 (Figure S1b) was used. The M-HKUST-1 was generated via isostructural substitution of $\mathrm{Cu}$ at all the metal ion sites of HKUST-1. Since the native metal center $\mathrm{Cu}$ in HKUST-1 exhibits +2 oxidation state, 18 -substituted metal elements $(\mathrm{M})$ potentially with a +2 oxidation state were selected: five alkaline earth metals $(\mathrm{Be}$, $\mathrm{Mg}$, Ca, Sr, and Ba), twelve transition metals ( $\mathrm{Sc}, \mathrm{Ti}, \mathrm{V}, \mathrm{Cr}, \mathrm{Mn}, \mathrm{Fe}, \mathrm{Co}, \mathrm{Ni}, \mathrm{Zn}, \mathrm{Mo}, \mathrm{W}$, and $\mathrm{Cd}$ ), and one Group IVA metal (Sn). Synthesis of microporous Be(Ba)-based MOFs is not easy in experiments but is nonetheless possible. Kang et al. [31] succeeded to synthesize Be-based MOFs, including $\mathrm{Be}_{2}(\mathrm{OH})_{2}(\mathrm{bdc})(\mathrm{BCF}-3)$ and $\mathrm{Be}_{4}(\mathrm{OH})_{4}(\mathrm{btec})(\mathrm{BCF}-4)$ (where bdc is 1,3-benzenedicarboxylate and btec is 1,2,4,5-benzenetetracarboxylate) under hydrothermal conditions.

We performed periodic density functional theory (DFT) calculations as implemented in Vienna ab-initio Package (VASP) [32,33] using the projector augmented wave method (PAW) [34] and the Perdew-Burke-Ernzerhof (PBE) [35] generalized gradient approximation of the exchange-correlation functional. Note that a series of previous theoretical studies demonstrated that dispersion-corrected 
functionals, such as DFT-D2, DFT-D3, and revPBE-vdW, provide the adsorption enthalpies in good agreement with the experimental value upon $\mathrm{CO}_{2}$ adsorption on CUS-MOFs [36-38]. While $\mathrm{CO}_{2}$ yields physical adsorption on CUS-MOFs, the interaction between NCCs molecules and M-HKUST-1 in our studies is mainly chemisorption [15]. Moreover, in this work, we are interested in the trend more than the absolute values, and previous studies [38] show that the PBE functional is good enough to describe the adsorption trend on various MOFs. All calculations are spin-polarized and the cutoff energy of basis set is $540 \mathrm{eV}$ [39]. Due to the large size of the unit cells, only the gamma $(1 \times 1 \times 1)$ point was used. The force tolerance on each atom between ion steps is relaxed to $0.03 \mathrm{eV} \AA^{-1}$. The climbing image nudged elastic band (CI-NEB) [40] method and dimer [41] algorithm are used to search for transition states. Seven geometry images in total are used for each CI-NEB cycle. We calculated the imaginary frequency to verify the transition state that has only one imaginary frequency.

For molecular adsorption, the adsorption energy at $0 \mathrm{~K} \Delta \mathrm{E}_{\text {ads }}$ is calculated by:

$$
\Delta \mathrm{E}_{\mathrm{ads}}=\mathrm{E}_{\text {total }}(\mathrm{MOFs}+\mathrm{N})-\mathrm{E}_{\text {total }}(\mathrm{MOFs})-\mathrm{E}_{\text {total }}(\mathrm{N})
$$

Here, $\mathrm{E}_{\text {total }}(\mathrm{MOFs}+\mathrm{N}), \mathrm{E}_{\text {total }}(\mathrm{MOFs})$, and $\mathrm{E}_{\text {total }}(\mathrm{N})$ refer to the total energies of the MOFs with the adsorbed nitrogen-containing compounds, the empty MOFs, and the nitrogen-containing compounds in the gas phase, respectively. For dissociative adsorption, here the dissociative adsorption energy at $0 \mathrm{~K} \Delta \mathrm{E}_{\text {ads-sep }}$ ' is calculated by:

$$
\begin{gathered}
\Delta \mathrm{E}_{\text {ads-sep }}{ }^{\prime}=\mathrm{E}_{\text {total }}\left(\mathrm{MOFs}+\mathrm{N}_{\mathrm{x} 1}\right)+\mathrm{E}_{\text {total }}\left(\mathrm{MOFs}+\mathrm{N}_{\mathrm{x} 2}\right)+\ldots+\mathrm{E}_{\text {total }}\left(\mathrm{MOFs}+\mathrm{N}_{\mathrm{xn}}\right) \\
-(\mathrm{n}-1) \mathrm{E}_{\text {total }}(\mathrm{MOFs})-\mathrm{E}_{\text {total }}(\mathrm{MOFs}+\mathrm{N})
\end{gathered}
$$

where the dissociated parts are at the infinite separation. $E_{\text {total }}\left(M O F s+N_{x n}\right)$ is the total energy of the adsorbed state where $\mathrm{N}_{\mathrm{xn}}$ denotes the dissociation of the adsorbed molecule into $n$ parts.

\section{Results and Discussion}

\subsection{Bulk Structure}

We first performed a geometric optimization of the bulk structure of 19 M-HKUST-1. The calculated $\mathrm{Cu}-\mathrm{Cu}$ distance in HKUST-1 is $2.46 \AA$, which is close to the previously calculated value of $2.52 \AA$ and shorted than the corresponding experimental value of $2.58 \AA$ [15]. The data in Table S1 show that the calculated lattice constants of the obtained variant structures are close to the available experimental values, smaller than $1.6 \%$.

According to the structure in the secondary building unit (SBU, Figure S1c), 14 M-HKUST-1 structures $(\mathrm{M}=\mathrm{Be}, \mathrm{Fe}, \mathrm{Ni}, \mathrm{Cr}, \mathrm{Co}, \mathrm{V}, \mathrm{Zn}, \mathrm{Mo}, \mathrm{Mn}, \mathrm{W}, \mathrm{Ti}, \mathrm{Cd}, \mathrm{Mg}$, and $\mathrm{Sc}$ ) of the 18 alternative metal-substituted variants retain the original structure with the distortion degree smaller than $36 \%$ (most smaller than 20\%), indicating the isostructural metal alternatives is possible. Four M-HKUST-1 variants $(\mathrm{M}=\mathrm{Sn}, \mathrm{Ca}$, $\mathrm{Sr}$, and $\mathrm{Ba})$ have undergone a distortion with enlarged $\mathrm{M}-\mathrm{M}$ distance, but retain the original crystal prototype of HKUST-1. The corresponding M-M distance is in the range of 3.54-4.19 A. Similar results were obtained by Koh et al. [36] from the revPBE-vdW functional. They also found M-HKUST-1 ( $\mathrm{M}=\mathrm{Sn}, \mathrm{Ca}$, and Sr) shows the largest distortion among their screened 18 metal substituted structures but still retains the original prototype structure. Connecting with the adsorption energy of NCC s on M-HKUST-1, the M-HKUST-1 ( $\mathrm{M}=\mathrm{Sn}, \mathrm{Ca}$, Sr, and $\mathrm{Ba}$ ) variants with the larger distortion exhibit a poor adsorption property among all screened structures. The metal center and its four bonded oxygen atoms in M-HKUST-1 (M = Sn, Ti, Cd, Mg, Sc, Ca, Sr, Ba) exhibit a square-pyramidal-like coordination. The corresponding dihedral angles between plane of $\mathrm{M}-\mathrm{O} 1-\mathrm{O} 2$ and the four-fold oxygen plane are larger than $9.5^{\circ}$ and the distances from the metal ion to the basal plane of $\mathrm{O}$ atoms $\mathrm{d}(\mathrm{M}-4 \mathrm{O})$ are larger than $2.5 \AA$. While the others exhibit a square-planar-like coordination with a corresponding dihedral angle smaller than $5.7^{\circ}$ and $d(\mathrm{M}-4 \mathrm{O})$ smaller than $1.4 \AA$. In particular, Sn-HKUST-1 and Ba-HKUST-1, square-pyramidal-like configurations, yield the largest 
M-M distances of 4.09 and $4.17 \AA$, respectively, and exhibit the worst adsorption behavior among the 19-screened structures.

\subsection{Molecular Adsorption}

According to the previous experimental $[12,13]$ and theoretical studies [23], the main reaction sites for $\mathrm{NO}, \mathrm{NO}_{2}$, and $\mathrm{NH}_{3}$ adsorption are under-coordinated "open-metal" sites. Chen et al. [23] studied the contribution of each fragment of metal-organic frameworks (MOFs), including HKUST-1 (MOF-199), to the adsorption of sulfur compounds $\left(\mathrm{CH}_{3} \mathrm{CH}_{2} \mathrm{SH}, \mathrm{CH}_{3} \mathrm{SCH}_{3}\right.$, and $\left.\mathrm{H}_{2} \mathrm{~S}\right)$ using density functional theory (DFT). They found MOFs with coordinatively unsaturated sites (CUS) have the strongest binding strength with sulfur compounds, and the organic ligands without substituent group has the weakest adsorption strength. Therefore, in the present study, only the under-coordinated "open-metal" sites are considered and the sites of the MOF ligands are ignored. Table 1 presents the adsorption energy and selected geometric parameters for the molecular adsorption of $\mathrm{NO}$ and $\mathrm{NH}_{3}$ molecules in M-HKUST-1.

Table 1. Calculated distances between the metal center and the nitrogen $d(M-N)(\AA), N-O$ bond lengths within $\mathrm{NO} d(\mathrm{~N}-\mathrm{O})(\AA)$, bond angles (Ang.) formed by the metal center of M-HKUST-1 and O and $\mathrm{N}$ in $\mathrm{NO}\left(^{\circ}\right)$ and adsorption energy $\Delta \mathrm{E}_{\text {ads }}\left(\mathrm{kJ} \mathrm{mol}^{-1}\right)$ for molecular adsorption of $\mathrm{NO}$ and $\mathrm{NH}_{3}$ on M-HKUST-1.

\begin{tabular}{|c|c|c|c|c|c|c|c|c|c|c|}
\hline & \multicolumn{3}{|l|}{ NO-t1 } & \multicolumn{4}{|c|}{ NO-t2 } & \multicolumn{3}{|c|}{$\mathrm{NH}_{3}$} \\
\hline & $\mathrm{d}(\mathrm{M}-\mathrm{N})$ & $d(N-O)$ & Ang. & $\Delta \mathrm{E}_{\mathrm{ads}}$ & $\mathrm{d}(\mathrm{M}-\mathrm{O})$ & $\mathrm{d}(\mathrm{N}-\mathrm{O})$ & Ang. & $\Delta \mathrm{E}_{\text {ads }}$ & $\mathrm{d}(\mathrm{M}-\mathrm{N})$ & $\Delta \mathrm{E}_{\text {ads }}$ \\
\hline gas & - & 1.17 & - & - & - & - & - & - & - & - \\
\hline $\mathrm{Be}$ & 1.96 & 1.17 & 174 & -20.0 & 2.23 & 1.17 & 168 & -0.4 & 1.75 & -136.7 \\
\hline $\mathrm{Fe}$ & 1.71 & 1.18 & 178 & -81.6 & 1.91 & 1.19 & 178 & -15.0 & 2.11 & -60.3 \\
\hline $\mathrm{Ni}$ & 1.81 & 1.18 & 122 & -157.0 & 3.30 & 1.17 & 140 & -3.4 & 2.07 & -95.2 \\
\hline $\mathrm{Cr}$ & 1.83 & 1.19 & 151 & -41.0 & 3.24 & 1.17 & 175 & -0.9 & 2.37 & -35.0 \\
\hline Co & 1.80 & 1.18 & 128 & -143.6 & 1.98 & 1.18 & 130 & -74.1 & 2.04 & -104.3 \\
\hline $\mathrm{Cu}$ & 1.97 & 1.17 & 126 & $-26.8(-21.31)^{1}$ & 3.07 & 1.16 & 157 & -11.1 & 2.20 & -79.8 \\
\hline $\mathrm{V}$ & 1.75 & 1.20 & 176 & -142.5 & 2.00 & 1.20 & 152 & -62.0 & 2.24 & -80.5 \\
\hline $\mathrm{Zn}$ & 2.21 & 1.17 & 129 & -37.2 & 2.50 & 1.17 & 179 & -12.3 & 2.06 & -128.7 \\
\hline Mo & 2.39 & 1.19 & 127 & -22.4 & 3.11 & 1.18 & 177 & -0.8 & 3.19 & -9.8 \\
\hline $\mathrm{Mn}$ & 1.66 & 1.18 & 179 & -196.5 & 1.81 & 1.19 & 178 & -67.3 & 2.32 & -51.1 \\
\hline W & 1.90 & 1.20 & 174 & -57.6 & 3.01 & 1.19 & 177 & -2.4 & 3.11 & -11.9 \\
\hline $\mathrm{Sn}$ & 4.11 & 1.17 & 173 & -0.9 & 4.40 & 1.17 & 177 & -0.5 & 4.09 & -0.8 \\
\hline $\mathrm{Ti}$ & 1.82 & 1.22 & 179 & -236.9 & 1.92 & 1.25 & 180 & -108.5 & 2.41 & -66.9 \\
\hline $\mathrm{Cd}$ & 2.45 & 1.17 & 130 & -32.6 & 2.71 & 1.17 & 180 & -8.8 & 2.30 & -109.6 \\
\hline $\mathrm{Mg}$ & 2.25 & 1.17 & 179 & -28.7 & 2.24 & 1.18 & 180 & -16.7 & 2.14 & -116.8 \\
\hline $\mathrm{Sc}$ & 2.04 & 1.22 & 159 & -174.8 & 2.04 & 1.25 & 149 & -118.8 & 2.38 & -86.5 \\
\hline $\mathrm{Ca}$ & 2.60 & 1.18 & 179 & -21.9 & 2.56 & 1.18 & 179 & -11.8 & 2.54 & -70.6 \\
\hline $\mathrm{Sr}$ & 2.78 & 1.19 & 177 & -19.4 & 2.73 & 1.19 & 180 & -12.4 & 2.76 & -53.1 \\
\hline $\mathrm{Ba}$ & 3.04 & 1.19 & 177 & -16.0 & 3.04 & 1.19 & 180 & -0.3 & 3.63 & -7.3 \\
\hline
\end{tabular}

\subsubsection{NO Adsorption}

NO adsorption on the metal site of M-HKUST-1 is via either its $\mathrm{O}$ end or $\mathrm{N}$ end (Figure S2). The adsorption via the $\mathrm{N}$ end of the $\mathrm{NO}$ molecule yields $\Delta \mathrm{E}_{\text {ads }}$ of $-26.8 \mathrm{~kJ} \mathrm{~mol}^{-1}$, which is close to the previously calculated value, $-21.3 \mathrm{~kJ} \mathrm{~mol}^{-1}$ [37], with formed M-N bond distance of $1.97 \AA$. The adsorption via the $\mathrm{O}$ end of $\mathrm{NO}$ molecule yields a higher adsorption energy of $-11.09 \mathrm{~kJ} / \mathrm{mol}$ with a larger M-O bond distance of $3.07 \AA$. The calculations show that NO adsorption on the Cu site of $\mathrm{Cu}$-HKUST- 1 by forming the M-N bond is more stable than by forming the M-O bond. Similar results have been observed for the other 18 alternative metal-substituted variants. NO adsorption on the M-HKUST- 1 via its $\mathrm{N}$ end is more stable than that via its $\mathrm{O}$ end. The strongest adsorption via $\mathrm{t} 2$ mode 
yields the adsorption energy of $-118.8 \mathrm{~kJ} \mathrm{~mol}^{-1}$ on Sc-HKUST-1, followed by the Ti-HKUST-1 with $\mathrm{E}_{\mathrm{ads}}$ of $-108.5 \mathrm{~kJ} \mathrm{~mol}^{-1}$. This is consistent with our previous observation about $\mathrm{NO}$ adsorption on the $\beta-\mathrm{Mo}_{2} \mathrm{C}(0001)$ surface [42]. NO preferred to adsorb on $\beta-\mathrm{Mo}_{2} \mathrm{C}(0001)$ via its $\mathrm{N}$ end compared to its $\mathrm{O}$ end.

The calculated M-N bond distance in $\mathrm{t} 1$ mode is between $1.66 \AA$ on Mn-HKUST-1 and $4.11 \AA$ on Sn-HKUST-1 in this study (Table 1). According to the M-N-O angle, the adsorption configurations can be divided into three groups: linear adsorption with the $\mathrm{M}-\mathrm{N}-\mathrm{O}$ angle of $\sim 180^{\circ}, \mathrm{NO}_{2}$-like adsorption with the $\mathrm{M}-\mathrm{N}-\mathrm{O}$ angle of $\sim 125^{\circ}$ which is close to $134^{\circ}$ (the $\mathrm{O}-\mathrm{N}-\mathrm{O}$ angle value of $\mathrm{NO}_{2}$ in the gas phase), and a bent adsorption with the M-N-O angle of $\sim 155^{\circ}$. NO adsorption on M-HKUST-1 $(\mathrm{M}=\mathrm{Be}, \mathrm{Fe}, \mathrm{V}, \mathrm{Mn}, \mathrm{W}, \mathrm{Sn}, \mathrm{Ti}, \mathrm{Mg}, \mathrm{Ca}, \mathrm{Sr}$, and $\mathrm{Ba}$ ) via $\mathrm{t} 1$ mode results in the linear adsorption mode; NO adsorption on Cr-HKUST-1 and Sc-HKUST-1 yields the M-N-O angle of $\sim 155^{\circ}$. Similar to the case on Cu-HKUST-1, NO adsorption via its N end on M-HKUST-1 (M = Ni, Co, Zn, Mo, and Cd) yields the $\mathrm{NO}_{2}$-like adsorption mode. The adsorption energy of the MOFs structure ranges from $-0.9 \mathrm{~kJ}$ $\mathrm{mol}^{-1}$ for Sn-HKUST-1 to $-236.9 \mathrm{~kJ} \mathrm{~mol}^{-1}$ for Ti-HKUST-1. From the thermodynamic point of view, among the above 19 MOFs structures, twelve alternative M-HKUST-1 (M = Ti, Mn, Sc, Ni, Co, V, $\mathrm{Fe}, \mathrm{W}, \mathrm{Cr}, \mathrm{Zn}, \mathrm{Cd}$, and $\mathrm{Mg}$ ) have the potential to exhibit a stronger $\mathrm{NO}$ adsorption capacity than the original Cu-HKUST-1.

\subsection{2. $\mathrm{NH}_{3}$ Adsorption}

For $\mathrm{NH}_{3}$ adsorption, we only consider one type of adsorption configuration: top adsorption on the metal center of M-HKUST-1 through the $\mathrm{N}$ end of the $\mathrm{NH}_{3}$ molecule (Figure S3).

The adsorption of the $\mathrm{NH}_{3}$ molecule on the $\mathrm{Cu}$ center of HKUST-1 yields the adsorption energy of $-79.8 \mathrm{~kJ} \mathrm{~mol}^{-1}$ with the formed M-N bond distance of $2.20 \AA$.

The MOFs synthesized from the metal centers $\mathrm{Be}, \mathrm{Zn}, \mathrm{Mg}, \mathrm{Cd}, \mathrm{Co}$, and $\mathrm{Ni}$ have much larger adsorption energy and shorter $\mathrm{M}-\mathrm{N}$ bond length than $\mathrm{Cu}-\mathrm{HKUST}-1$ upon $\mathrm{NH}_{3}$ adsorption. Among them, Be-HKUST-1 exhibits the best adsorption performance with the largest adsorption energy $\Delta \mathrm{E}_{\text {ads }}$ of $-136.7 \mathrm{~kJ} \mathrm{~mol}^{-1}$ and shortest $\mathrm{M}-\mathrm{N}$ bond distance of $1.75 \AA$. Compared with the $\mathrm{M}-\mathrm{N}$ distance of $4.09 \AA$ and the adsorption energy of $-0.8 \mathrm{~kJ} \mathrm{~mol}^{-1}$ on Sn-HKUST-1, the superiority of its adsorption performance for $\mathrm{NH}_{3}$ was more prominent. In addition, when Ti-HKUST-1 exhibits excellent adsorption performance for $\mathrm{NO}$, it also shows good adsorption performance for $\mathrm{NH}_{3}$, but it is less favorable than Cu-HKUST-1 with adsorption energy of $-66.9 \mathrm{~kJ} \mathrm{~mol}^{-1}$, which is about $13 \mathrm{~kJ} \mathrm{~mol}^{-1}$ higher than that of the latter.

\subsection{3. $\mathrm{NO}_{2}$ Adsorption}

For $\mathrm{NO}_{2}$ adsorption, we considered four possible adsorption geometries: top adsorption through the $\mathrm{N}$ end of $\mathrm{NO}_{2}$ molecule (t1), top adsorption through the $\mathrm{O}$ end of $\mathrm{NO}_{2}$ molecule (t2), bridge adsorption with two oxygen atoms binding to one open metal site (b1), and bridge adsorption with one $\mathrm{N}$ and one $\mathrm{O}$ atom binding to one open metal site (b2). Table 2 and Table $\mathrm{S} 2$ list the adsorption energy and selected geometric parameters.

The most stable adsorption configuration for $\mathrm{NO}_{2}$ molecular adsorption on the original $\mathrm{Cu}-\mathrm{HKUST}-1$ is the $\mathrm{t} 2$ mode by forming one $\mathrm{M}-\mathrm{O}$ bond. The corresponding $\mathrm{M}-\mathrm{O}$ bond distance and adsorption energy is $2.24 \AA$ and $-40.8 \mathrm{~kJ} \mathrm{~mol}^{-1}$, respectively. The $\mathrm{t} 1$ mode by forming one $\mathrm{M}-\mathrm{N}$ bond yields a much higher adsorption energy of $-13.2 \mathrm{~kJ} \mathrm{~mol}^{-1}$. All attempts to get b1 and b2 structure convert to the $\mathrm{t} 2$ and $\mathrm{t} 1$ modes.

Our calculations show that the strong interaction between the metal center and $\mathrm{N}(\mathrm{O})$ end in $\mathrm{NO}_{2}$ yields a significant reduction of the $\mathrm{N}-\mathrm{O}$ bond near the substituted metal center which weakens the $\mathrm{N}-\mathrm{O}$ bond strength within the $\mathrm{NO}_{2}$ molecule (see Figure $\mathrm{S} 4$ ). As a result, the $\mathrm{N}-\mathrm{O}$ bond in adsorbed $\mathrm{NO}_{2}$ structure is observed to undergo elongation. We found two $\mathrm{N}-\mathrm{O}$ bond lengths of the adsorbed $\mathrm{NO}_{2}$ in the $\mathrm{t} 1$ and $\mathrm{b} 1$ modes are identical, while in the $\mathrm{t} 2$ and $\mathrm{b} 2$ modes the $\mathrm{N}-\mathrm{O}$ bond distances near the substituted metal center are shorter than those away from the substrate. The N-O bond length 
ranges from $1.21 \AA$ on Be-HKUST- 1 to $1.25 \AA$ on Ba-HKUST- 1 in t1 mode. While in the t 2 mode, the N-O bond length near the bonded metal center yields the range from $1.24 \AA$ on Cu-HKUST-1 to $1.42 \AA$ on Sn-HKUST- 1 and the N-O bond length away from the substrate gives the range of 1.21-1.24 $\AA$. The average differences between two N-O bond distances are $0.08 \AA$ and $0.09 \AA$ for $\mathrm{t} 2$ and b2 modes, respectively.

Table 2. Calculated adsorption energy $\Delta \mathrm{E}_{\mathrm{ads}}\left(\mathrm{kJ} \mathrm{mol}^{-1}\right)$ and metal-nitrogen/oxygen bond length $\mathrm{d}(\mathrm{M}-\mathrm{N} / \mathrm{O})(\AA)$ between the center of the metal and nitrogen or oxygen in $\mathrm{NO}_{2}$ for molecular adsorption of $\mathrm{NO}_{2}$ on M-HKUST-1. The $\Delta \mathrm{E}_{\mathrm{ads}}$ values for the most stable adsorption mode are labeled in bold.

\begin{tabular}{ccccccccc}
\hline & \multicolumn{2}{c}{$\mathbf{( t 1 )}$} & \multicolumn{2}{c}{$\mathbf{( t 2 )}$} & \multicolumn{2}{c}{$\mathbf{( b 1 )}$} & \multicolumn{2}{c}{ (b2) } \\
\hline & $\mathbf{d}(\mathbf{M}-\mathbf{N})$ & $\mathbf{\Delta} \mathbf{E}_{\mathbf{a d s}}$ & $\mathbf{d}(\mathbf{M}-\mathbf{O})$ & $\boldsymbol{\Delta} \mathbf{E}_{\mathbf{a d s}}$ & $\mathbf{d}\left(\mathbf{M}-\mathbf{O} / \mathbf{O}^{\prime}\right)$ & $\boldsymbol{\Delta} \mathbf{E}_{\mathbf{a d s}}$ & $\mathbf{d}(\mathbf{M}-\mathbf{N} / \mathbf{O})$ & $\Delta \mathbf{E}_{\mathbf{a d s}}$ \\
\hline $\mathrm{Be}$ & 2.68 & -2.9 & 1.74 & $-\mathbf{3 1 . 4}$ & $\mathrm{b} 1 \rightarrow \mathrm{t} 2$ & - & $\mathrm{b} 2 \rightarrow \mathrm{t} 2$ & - \\
$\mathrm{Fe}$ & 2.03 & $-\mathbf{1 6 4 . 0}$ & 2.00 & -85.1 & $\mathrm{~b} 1 \rightarrow \mathrm{t} 2$ & - & $\mathrm{b} 2 \rightarrow \mathrm{t} 1$ & - \\
$\mathrm{Ni}$ & 1.94 & $-\mathbf{1 0 5 . 0}$ & 1.99 & -66.6 & $\mathrm{~b} 1 \rightarrow \mathrm{t} 2$ & - & $\mathrm{b} 2 \rightarrow \mathrm{t} 1$ & - \\
$\mathrm{Cr}$ & $\mathrm{t} 1 \rightarrow \mathrm{b} 2$ & - & 2.03 & -64.5 & $\mathrm{~b} 1 \rightarrow \mathrm{t} 2$ & - & $1.99 / 2.31$ & $\mathbf{- 2 2 2 . 5}$ \\
$\mathrm{Co}$ & 1.95 & $-\mathbf{1 1 5 . 9}$ & 1.97 & -82.1 & $\mathrm{~b} 1 \rightarrow \mathrm{t} 2$ & - & $\mathrm{b} 2 \rightarrow \mathrm{t} 1$ & - \\
$\mathrm{Cu}$ & 2.22 & -13.2 & 2.24 & $-\mathbf{4 0 . 8}$ & $\mathrm{b} 1 \rightarrow \mathrm{t} 2$ & - & $\mathrm{b} 2 \rightarrow \mathrm{t} 1$ & - \\
$\mathrm{V}$ & 2.15 & -82.2 & 1.89 & -116.5 & $\mathrm{~b} 1 \rightarrow \mathrm{t} 2$ & - & $2.07 / 2.22$ & $\mathbf{- 1 2 5 . 4}$ \\
$\mathrm{Zn}$ & 2.19 & -11.3 & 2.08 & $-\mathbf{3 1 . 2}$ & $\mathrm{b} 1 \rightarrow \mathrm{t} 2$ & - & $\mathrm{b} 2 \rightarrow \mathrm{t} 2$ & - \\
$\mathrm{Mo}$ & 2.48 & -24.1 & 2.42 & $-\mathbf{2 8 . 0}$ & $\mathrm{b} 1 \rightarrow \mathrm{t} 2$ & - & $\mathrm{b} 2 \rightarrow \mathrm{t} 1$ & - \\
$\mathrm{Mn}$ & 2.05 & -94.5 & 1.93 & $-\mathbf{1 2 5 . 2}$ & $\mathrm{b} 1 \rightarrow \mathrm{t} 2$ & - & $\mathrm{b} 2 \rightarrow \mathrm{t} 1$ & - \\
$\mathrm{W}$ & 2.40 & -46.3 & 2.32 & $-\mathbf{5 2 . 2}$ & $\mathrm{b} 1 \rightarrow \mathrm{t} 2$ & - & $\mathrm{b} 2 \rightarrow \mathrm{t} 1$ & - \\
$\mathrm{Sn}$ & 3.39 & -4.6 & 2.04 & -6.6 & $2.88 / 2.94$ & $-\mathbf{1 4 . 5}$ & $\mathrm{b} 2 \rightarrow \mathrm{t} 1$ & - \\
$\mathrm{Ti}$ & $\mathrm{t} 1 \rightarrow \mathrm{b} 2$ & - & $\mathrm{t} 2 \rightarrow \mathrm{b} 1$ & - & $2.20 / 2.19$ & -224.0 & $2.05 / 1.99$ & $-\mathbf{2 4 5 . 5}$ \\
$\mathrm{Cd}$ & 2.43 & -11.5 & 2.41 & $-\mathbf{2 7 . 9}$ & $\mathrm{b} 1 \rightarrow \mathrm{t} 2$ & - & $\mathrm{b} 2 \rightarrow \mathrm{t} 1$ & - \\
$\mathrm{Mg}$ & 2.28 & -5.7 & 2.08 & $-\mathbf{4 0 . 6}$ & $\mathrm{b} 1 \rightarrow \mathrm{t} 2$ & - & $\mathrm{b} 2 \rightarrow \mathrm{t} 2$ & - \\
$\mathrm{Sc}$ & $\mathrm{t} 1 \rightarrow \mathrm{b} 2$ & - & 2.02 & -289.9 & $2.27 / 2.27$ & $-\mathbf{3 0 3 . 6}$ & $2.25 / 2.12$ & -295.9 \\
$\mathrm{Ca}$ & $\mathrm{t} 1 \rightarrow \mathrm{t} 2$ & - & 2.43 & $-\mathbf{4 2 . 1}$ & $2.63 / 2.62$ & -32.9 & $\mathrm{~b} 2 \rightarrow \mathrm{t} 2$ & - \\
$\mathrm{Sr}$ & $\mathrm{t} 1 \rightarrow \mathrm{t} 2$ & - & 2.60 & $-\mathbf{4 3 . 8}$ & $2.75 / 2.86$ & -40.0 & $\mathrm{~b} 2 \rightarrow \mathrm{t} 2$ & - \\
$\mathrm{Ba}$ & 3.02 & -33.8 & 2.85 & $-\mathbf{4 3 . 9}$ & $2.98 / 3.06$ & -43.6 & $\mathrm{~b} 2 \rightarrow \mathrm{t} 2$ & - \\
\hline
\end{tabular}

The calculations show that the $\mathrm{NO}_{2}$ adsorption on alkaline earth metal substituted variants follows the sequence: Be-HKUST-1 < Mg-HKUST-1 < Ca-HKUST- $1<$ Sr-HKUST- $1<$ Ba-HKUST-1, while the $\mathrm{NH}_{3}$ adsorption exhibits different adsorption behavior towards the substitution of $\mathrm{Cu}$ center by the alkaline earth metal. The adsorption ability follows the sequence in the reverse order: Be-HKUST-1 $>$ Mg-HKUST-1 > Ca-HKUST-1 > Sr-HKUST-1 > Ba-HKUST-1. Among these, the energetically most favorable center is Be-HKUST-1, with the lowest adsorption energy of $-136.7 \mathrm{~kJ} \mathrm{~mol}^{-1}$.

Based on the above description, Ti-HKUST-1 exhibits the best adsorption performance for NO adsorption, and it also shows an excellent adsorption behavior towards $\mathrm{NO}_{2}$ adsorption, which is better than Cu-HKUST-1 and only worse than Sc-HKUST-1. Sc-HKUST-1 is found to yield the best adsorption performance upon $\mathrm{NO}_{2}$ adsorption; see Figure 1. While for $\mathrm{NH}_{3}$ adsorption, Ti-HKUST-1 shows a slightly weaker adsorption property than Cu-HKUST-1. Instead, Be-HKUST-1 has the best adsorption effect for $\mathrm{NH}_{3}$. It should be noted that M-HKUST-1 $(\mathrm{M}=\mathrm{Ni}, \mathrm{Co}, \mathrm{V}$, and Sc) exhibits a better adsorption performance than Cu-HKUST-1 for three NCCs. The adsorption performance of Sn-HKUST-1 on the above gases is poor. As shown in Table S1, Table 1, and Table 2, when the structure of the M-HKUST-1 is deformed, it has relatively smaller adsorption energy, resulting in a poor adsorption performance. 


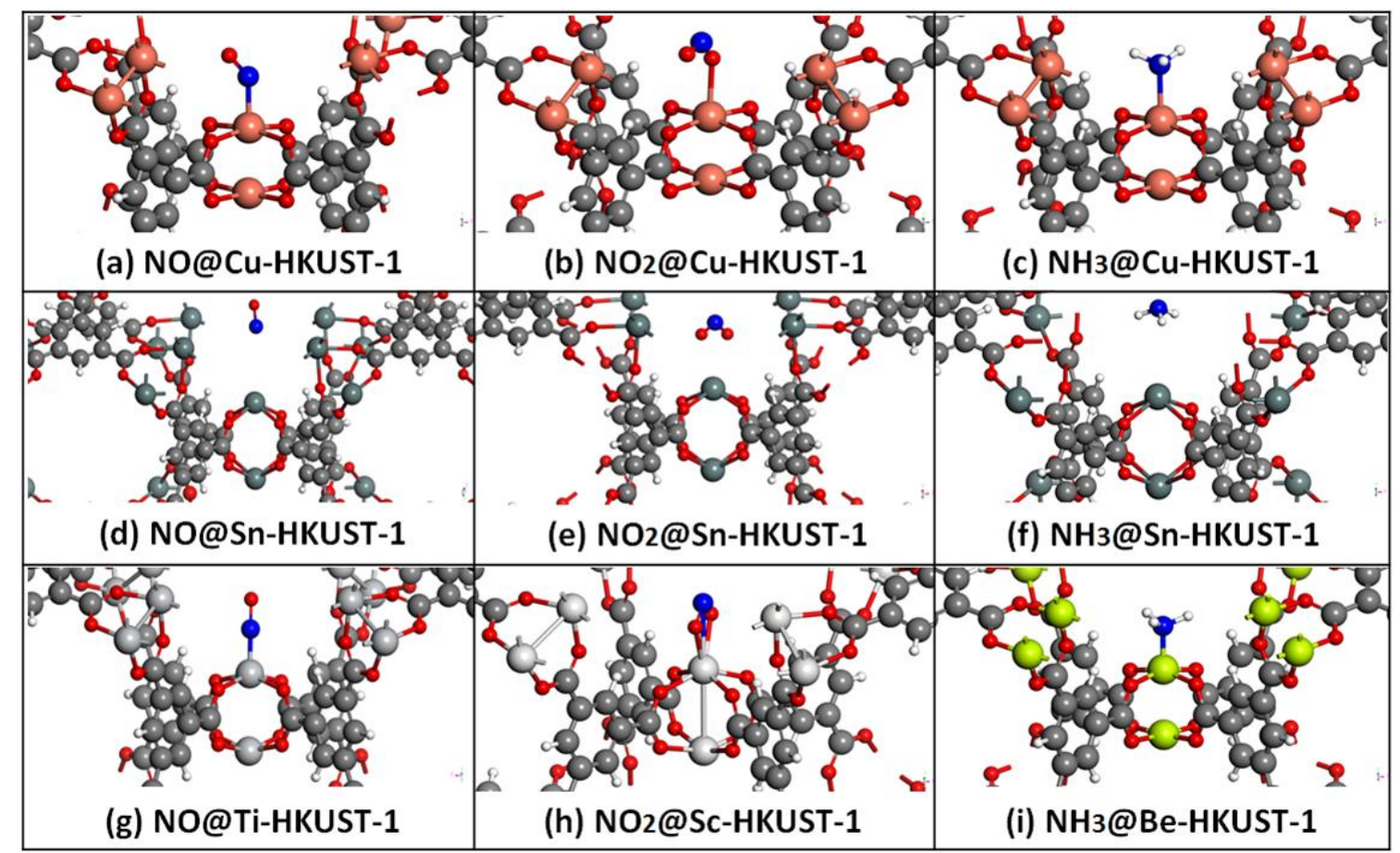

Figure 1. Representative adsorption structures near the secondary building units (SBUs) on selected metal organic frameworks (MOFs): (a) NO on Cu-HKUST-1, (b) $\mathrm{NO}_{2}$ on Cu-HKUST-1, (c) $\mathrm{NH}_{3}$ on Cu-HKUST-1, (d) NO on Sn-HKUST-1, (e) $\mathrm{NO}_{2}$ on Sn-HKUST-1, (f) $\mathrm{NH}_{3}$ on Sn-HKUST-1, (g) NO on Ti-HKUST-1, (h) $\mathrm{NO}_{2}$ on Sc-HKUST-1, and (i) $\mathrm{NH}_{3}$ on Be-HKUST-1. The largest spheres are metal atoms. White, red, blue, and grey spheres are $\mathrm{H}, \mathrm{O}, \mathrm{N}$, and $\mathrm{C}$ atoms with increasing size, respectively.

\subsection{Dissociative Adsorption}

Since the original metal center of HKUST-1 is $\mathrm{Cu}$, we first investigate the dissociation adsorption of NCC s on Cu-HKUST-1.

Considering the separation adsorption of nitrogen and oxygen at infinite position on HKUST-1, the dissociation energy $\Delta \mathrm{E}_{\text {ads-sep }}$ of $\mathrm{NO}$ is $586.9 \mathrm{~kJ} \mathrm{~mol}^{-1}$, suggesting the dissociative $\mathrm{NO}$ adsorption is strongly endothermic. The dissociative adsorption energy shifts significantly to more positive $\mathrm{E}_{\mathrm{ads}}$ values compared with the results for molecular adsorption. Therefore, the dissociative adsorption of $\mathrm{NO}$ is much less favorable than molecular adsorption thermodynamically suggesting strongly that NO will not dissociate on Cu-HKUST-1. All attempts to obtain the co-adsorption of $\mathrm{N}$ and $\mathrm{O}$ on the same $\mathrm{Cu}$ center resulted in the molecular adsorption of NO. Thus, there was no barrier search for NO dissociation on HKUST-1.

In the process of dissociative adsorption of $\mathrm{NO}_{2}$ to yield the products at the separated adsorption, the dissociation energies for the first and second steps are 318.0 and $586.9 \mathrm{~kJ} \mathrm{~mol}^{-1}$, respectively. Both steps are strongly endothermic indicating that the dissociation is unfavorable thermodynamically. Again, all attempts to obtain the co-adsorption of $\mathrm{NO}$ and $\mathrm{O}$ on the same $\mathrm{Cu}$ center resulted in the molecular adsorption of the $\mathrm{NO}_{2}$ molecule. Therefore, it can be concluded that $\mathrm{NO}$ and $\mathrm{NO}_{2}$ have rare possibility of dissociation to yield co-adsorption products on HKUST-1.

The energy profile of reaction paths for $\mathrm{NH}_{3}$ dissociation adsorption on $\mathrm{Cu}-\mathrm{HKUST}-1$ is provided in Figure 2. The reaction energy $\Delta \mathrm{E}_{\text {ads-sep }}$ for the dehydrogenation of $\mathrm{NH}_{3}$ to yield $\mathrm{NH}_{2}$ on the metal center and $\mathrm{H}$ on the oxygen atom in the absence of any lateral interactions was found to be strongly endothermic by $279.9 \mathrm{~kJ} \mathrm{~mol}^{-1}$. In the most stable co-adsorption configuration of hydrogen and $\mathrm{NH}_{2}$, $\mathrm{NH}_{2}$ adsorbs on the open $\mathrm{Cu}$ center while $\mathrm{H}$ prefers the neighboring oxygen center, which results in the cleavage of the $\mathrm{O}-\mathrm{Cu}$ bond. Consequently, the reaction energy changed to $330.5 \mathrm{~kJ} \mathrm{~mol}^{-1}$, indicating the reaction is still strongly endothermic. A further dehydrogenation of $\mathrm{NH}_{2}$ to produce 
$\mathrm{NH}$ and $\mathrm{H}$ yields a large reaction barrier of $458.2 \mathrm{~kJ} \mathrm{~mol}^{-1}$. The corresponding reaction energy is $192.8 \mathrm{~kJ} \mathrm{~mol}^{-1}$ with $\mathrm{NH}$ and $\mathrm{H}$ at infinite separation. When $\mathrm{NH}_{2}$ adsorbs on the open Cu center and $\mathrm{H}$ co-adsorbed on the neighboring oxygen center, the reaction energy changed to $185.1 \mathrm{~kJ} \mathrm{~mol}^{-1}$. The final dehydrogenation of $\mathrm{NH}$ to $\mathrm{N}$ and $\mathrm{H}$ is connected with a reaction barrier of $207.3 \mathrm{~kJ} \mathrm{~mol}^{-1}$ and dissociation energy of $190.1 \mathrm{~kJ} \mathrm{~mol}^{-1}$. As described above, the reaction energy and barrier for all dissociative adsorption processes are high; therefore, the possibility of dissociative adsorption is essentially eliminated thermodynamically and kinetically.

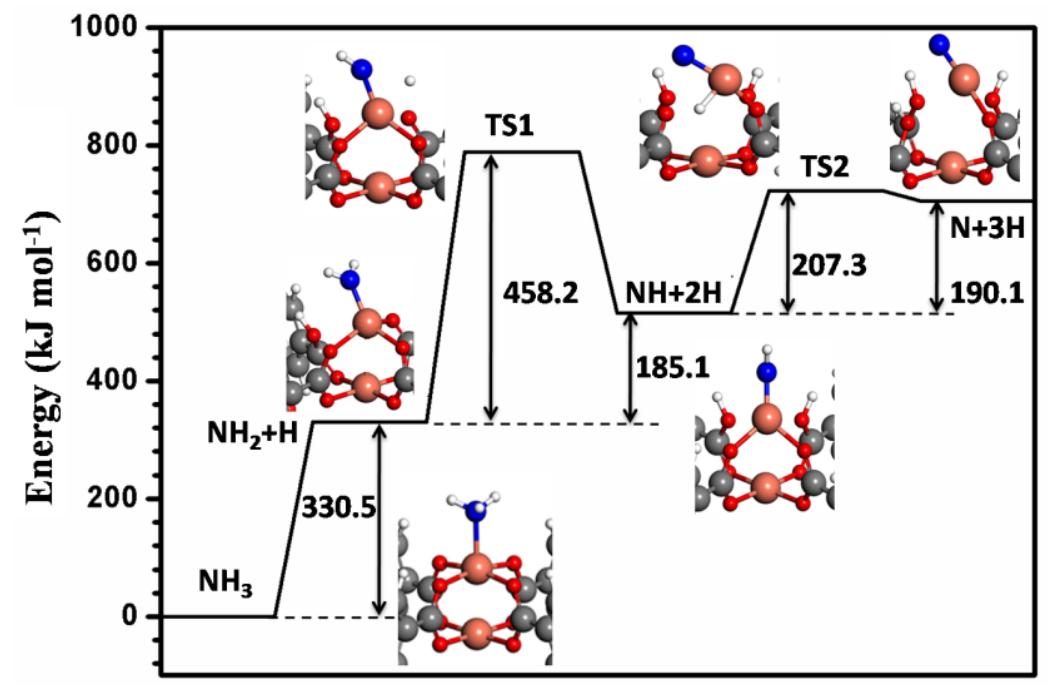

Figure 2. Reaction paths for $\mathrm{NH}_{3}$ dissociative adsorption on $\mathrm{Cu}-\mathrm{HKUST}-1$. TS1 is the transition state for $\mathrm{NH}_{2}$ dissociation into $\mathrm{NH}+\mathrm{H}$. TS2 is the transition state for $\mathrm{NH}$ dissociation to $\mathrm{N}+\mathrm{H}$. Adsorbate geometries present in the local MOFs region. The color scheme is the same as for Figure 1.

Based on the discussion in Section 3.1, we then chose 11 out of 19 candidates to study the dissociative adsorption, as provided in Table 3. Among them, Ti-HKUST-1, Sc-HKUST-1, and Be-HKUST-1 exhibit the most stable $\mathrm{NO}, \mathrm{NO}_{2}$, and $\mathrm{NH}_{3}$ molecular adsorption, respectively. M-HKUST-1 ( $\mathrm{M}=\mathrm{Sn}, \mathrm{Cd}, \mathrm{Ba}$ ) exhibits the least stable NCCs molecular adsorption and M-HKUST-1(M $=\mathrm{Ni}, \mathrm{Co}$, and $\mathrm{V}$ ) yields a better adsorption effect than Cu-HKUST-1 for three NCCs. Fe-HKUST-1 is also picked due to its excellent adsorption performance for $\mathrm{NO}$ and $\mathrm{NO}_{2}$ adsorption. To study the dissociation, we first investigate the adsorption of the dissociated species, e.g., $\mathrm{NH}_{\mathrm{x}}(\mathrm{x}=0-2)$, atomic $\mathrm{H}$ and atomic $\mathrm{O}$. The calculations show that $\mathrm{O}$ binds to the metal sites of M-HKUST-1 more strongly than $\mathrm{NH}_{\mathrm{x}}(\mathrm{x}=0-2)$ species with larger adsorption energies suggesting that atomic oxygen will compete with the dissociated $\mathrm{NH}_{\mathrm{x}}$ species for the open metal sites strongly and will block $\mathrm{NH}_{\mathrm{x}}$ adsorption. As shown in Table 3, the dissociative adsorption yields the energy ranges (in kJ mol ${ }^{-1}$ ) of -147.1 to 649.8, -174.9 to 355.6 , and -2.9 to 351.0 for $\mathrm{NO}, \mathrm{NO}_{2}$, and $\mathrm{NH}_{3}$ adsorption, respectively. It shifts to more positive $\Delta \mathrm{E}_{\mathrm{ads}}$ values (in $\mathrm{kJ} \mathrm{mol}^{-1}$ ) compared with the corresponding values for molecular adsorption with -236.9 to $-0.9,-303.6$ to -11.4 , and -136.7 to -0.8 , respectively. This means that dissociative adsorption is less likely to happen compared with the molecular adsorption thermodynamically. However, there is one exception: $\mathrm{NO}_{2}$ adsorption on V-HKUST-1 prefers to dissociate into NO and $\mathrm{O}$, and the yielded $\mathrm{NO}$ will retain the molecular adsorption with no further dissociation into $\mathrm{N}$ and O thermodynamically.

Overall, except for $\mathrm{NO}_{2}$ adsorption on V-HKUST-1, the dissociative $\mathrm{NO}, \mathrm{NO}_{2}$, and $\mathrm{NH}_{3}$ adsorption is less able to happen compared with the molecular adsorption thermodynamically and kinetically. 
Table 3. The dissociative adsorption energy $\Delta \mathrm{E}_{\text {ads-sep }}{ }^{\prime}\left(\mathrm{kJ} \mathrm{mol}^{-1}\right)$ of nitrogen-containing compounds on selected M-HKUST-1.

\begin{tabular}{ccccccc}
\hline & $\mathbf{N O} \rightarrow \mathbf{N}+\mathbf{O}$ & $\mathbf{N O}_{2} \rightarrow \mathbf{N O}+\mathbf{O}$ & $\mathbf{N O}_{2} \rightarrow \mathbf{N}+\mathbf{2 O}$ & $\mathbf{M H}_{\mathbf{3}} \rightarrow \mathbf{N H}_{\mathbf{2}}+\mathbf{H}$ & $\mathbf{N H}_{3} \rightarrow \mathbf{N H}+\mathbf{2} \mathbf{H}$ & $\mathbf{N H} \rightarrow \mathbf{N}+\mathbf{3 H}$ \\
\hline gas & 734.7 & 446.1 & 1180.8 & 471.2 & 887.6 & 1260.2 \\
$\mathrm{Be}$ & 619.3 & 329.3 & 948.6 & $284.1^{2}$ & $691.8^{2}$ & $1221.5^{2}$ \\
$\mathrm{Fe}$ & 299.8 & 133.3 & 433.1 & $189.1^{1}$ & $516.2^{2}$ & $550.0^{1}$ \\
$\mathrm{Ni}$ & 484.3 & 123.0 & 607.3 & $267.3^{2}$ & $543.2^{2}$ & $753.6^{2}$ \\
$\mathrm{Co}$ & 397.4 & 99.9 & 497.3 & $264.4^{1}$ & $542.3^{1}$ & $739.1^{1}$ \\
$\mathrm{Cu}$ & 586.9 & 318.0 & 904.9 & $279.9^{2}$ & $472.7^{2}$ & $662.9^{2}$ \\
$\mathrm{~V}$ & -139.2 & -174.9 & -314.1 & $200.7^{2}$ & $353.1^{2}$ & $506.6^{2}$ \\
$\mathrm{Sn}$ & 336.8 & 132.5 & 469.3 & $268.2^{2}$ & $581.8^{2}$ & $946.5^{2}$ \\
$\mathrm{Ti}$ & -147.1 & -162.4 & -309.5 & $-2.9^{1}$ & $100.3^{1}$ & $316.5^{1}$ \\
$\mathrm{Cd}$ & 649.8 & 339.7 & 989.5 & $351.0^{2}$ & $667.4^{2}$ & $927.1^{2}$ \\
$\mathrm{Sc}$ & 51.8 & -36.7 & 15.1 & $153.8^{2}$ & $570.6^{2}$ & $1031.8^{2}$ \\
$\mathrm{Ba}$ & 622.9 & 355.6 & 978.5 & $295.2^{2}$ & $594.3^{2}$ & $843.3^{2}$ \\
\hline
\end{tabular}

${ }^{1} \mathrm{H}$ at metal center; ${ }^{2} \mathrm{H}$ at the $\mathrm{O}$ near the metal center.

\subsection{Thermodynamics}

The NCC adsorption process on MOFs is described by the following equilibrium reaction:

$$
\text { MOFs }+ \text { NCCs (gas) } \leftrightarrow \text { NCCs-MOFs }
$$

Similar to our previous work [43], the corresponding adsorption Gibbs free energy, $\Delta G_{\text {ads }}(T, P)$, is calculated by

$$
\Delta \mathrm{G}_{\mathrm{ads}}(\mathrm{T}, \mathrm{P})=\Delta \mathrm{E}_{\mathrm{ads}}-\mathrm{G}^{\theta}(\mathrm{T})-\mathrm{RT} \ln \left(\mathrm{P}_{\mathrm{NCCs}} / \mathrm{P}^{\theta}\right)
$$

where $\Delta \mathrm{E}_{\mathrm{ads}}$ is the adsorption energy at $0 \mathrm{~K}$, and $\mathrm{G}^{\theta}(\mathrm{T})$ represents the thermo items including the contributions from translation, rotation, and vibration of the gas phase NCCs.

The corresponding results are shown in Figures 3 and 4. In Figure 3, we provide adsorption Gibbs free energy of $\mathrm{NO}, \mathrm{NO}_{2}$, and $\mathrm{NH}_{3}$ adsorption on various M-HKUST-1 as a function of the NCC chemical potential. The NCC chemical potential is correlated with pressure for room temperature (RT) as is characteristic of real temperatures employed in experiments $[13,44,45]$.

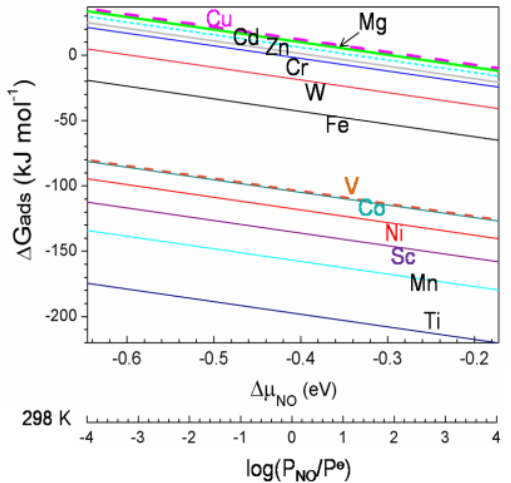

(a)

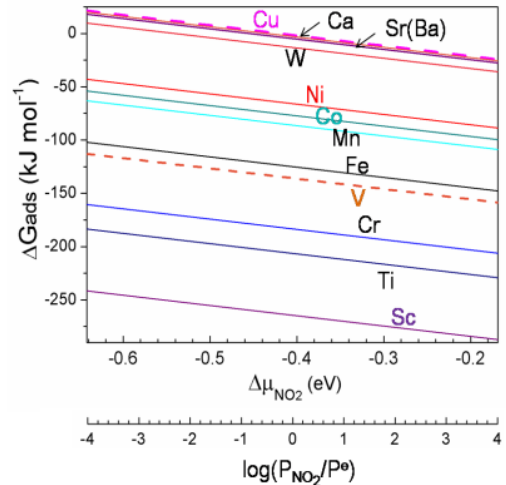

(b)

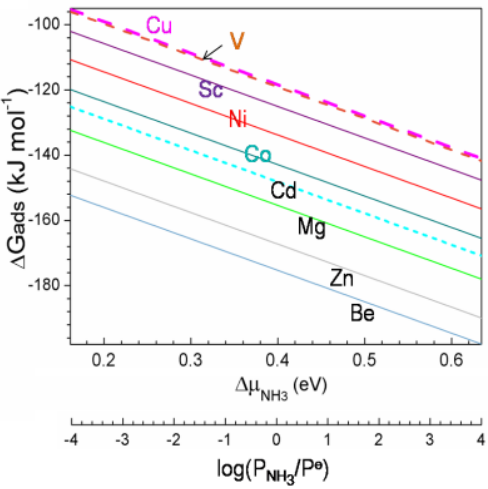

(c)

Figure 3. Adsorption Gibbs free energy, $\Delta \mathrm{G}_{\mathrm{ads}}\left(\mathrm{T}, \mathrm{P}\right.$ ) of (a) $\mathrm{NO},(\mathbf{b}) \mathrm{NO}_{2}$, and (c) $\mathrm{NH}_{3}$ adsorption on various M-HKUST-1 as a function of the nitrogen-containing compound (NCC) chemical potential, where $\mu_{\mathrm{NCCs}}$ is defined as $\mathrm{G}^{\theta}(\mathrm{T})+\mathrm{RT} \ln \left(\mathrm{P}_{\mathrm{NCC}} / \mathrm{P}^{\theta}\right)$ including zero-point vibrational energy. The corresponding pressure is provided for the selected temperature. To make the picture clear, only those with larger $\Delta \mathrm{G}_{\mathrm{ads}}(\mathrm{T}, \mathrm{P})$ than $\mathrm{Cu}-\mathrm{HKUSU}-1$ are included in the figure. 


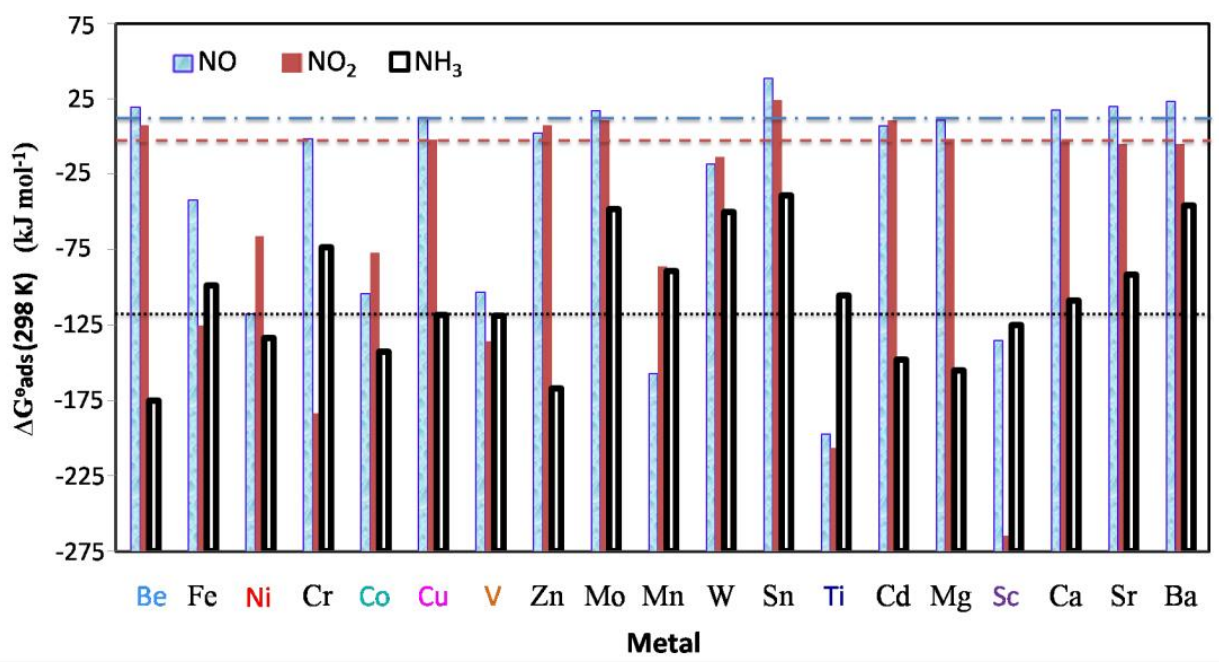

Figure 4. Standard adsorption Gibbs free energy $\Delta \mathrm{G}^{\theta}$ ads $(298 \mathrm{~K})$ of $\mathrm{NO}, \mathrm{NO}_{2}$, and $\mathrm{NH}_{3}$ adsorption on metal substituted variants of HKUST- 1 with the partial pressure of NCCs at $1 \mathrm{~atm}$. The blue dash $\mathrm{dot} / \mathrm{red}$ dash/dark dot line corresponds to the $\Delta \mathrm{G}^{\theta}$ ads $(298 \mathrm{~K})$ value of $\mathrm{NO} / \mathrm{NO}_{2} / \mathrm{NH}_{3}$ adsorption on Cu-HKUST-1. The shorter the bar, the stronger the binding.

It can be seen that twelve metal-substituted variants are predicted to be more suitable for NO adsorption than the original Cu-HKUST- 1 in a pressure region of $10^{-4}-10^{4} \mathrm{~atm}$ at $298 \mathrm{~K}$. The metal center yields the stability of $\mathrm{NO}$ adsorption in a decreased sequence: $\mathrm{Ti}>\mathrm{Mn}>\mathrm{Sc}>\mathrm{Ni}>\mathrm{Co} \approx$ $\mathrm{V}>\mathrm{Fe}>\mathrm{W}>\mathrm{Cr}>\mathrm{Zn}>\mathrm{Cd}>\mathrm{Mg} \approx \mathrm{Cu}$. The NO adsorption on Cu-HKUST-1 becomes favorable thermodynamically when $\mathrm{NO}$ chemical potential is larger than $-0.24 \mathrm{eV}$, corresponding to NO pressure higher than $165 \mathrm{~atm}$ at $298 \mathrm{~K}$.

Twelve (eight) variants of M-HKUST-1 have the potential to exhibit better performance for $\mathrm{NO}_{2}$ $\left(\mathrm{NH}_{3}\right)$ capture than Cu-HKUST-1. The corresponding stability of $\mathrm{NO}_{2}$ adsorption on M-HKUST-1 decreased in sequence: $\mathrm{Sc}>\mathrm{Ti}>\mathrm{Cr}>\mathrm{V}>\mathrm{Fe}>\mathrm{Mn}>\mathrm{Co}>\mathrm{Ni}>\mathrm{W}>\mathrm{Sr} \approx \mathrm{Ba}>\mathrm{Ca}>\mathrm{Cu}$. For $\mathrm{NH}_{3}$ adsorption, the sequence changed to $\mathrm{Be}>\mathrm{Zn}>\mathrm{Mg}>\mathrm{Cd}>\mathrm{Co}>\mathrm{Ni}>\mathrm{Sc}>\mathrm{V} \approx \mathrm{Cu}$. The thermodynamical analysis also shows that the $\mathrm{NO}_{2}$ adsorption on Cu-HKUST-1 becomes exothermic with the $\mathrm{NO}_{2}$ partial pressure higher than $\sim 0.5 \mathrm{~atm}$ at $298 \mathrm{~K}$ connected with $\mathrm{NO}_{2}$ chemical potential larger than -0.38 $\mathrm{eV}$. $\mathrm{NH}_{3}$ adsorption on all considered M-HKUST- 1 is exothermic in our considered $\mathrm{NH}_{3}$ chemical potential range indicating it is always favorable thermodynamically in our considered range.

Adsorption Gibbs free energies on 19 M-HKUST-1 (Figure 4) shows that five alkaline earth metals together with $\mathrm{Zn}, \mathrm{Mo}$, and $\mathrm{Sn}$ show the same trend with Cu-HKUST-1 towards three NCCs adsorption and the stability order is: $\mathrm{NH}_{3}>\mathrm{NO}_{2}>\mathrm{NO}$. A similar result was observed by Supronowicz et al. [11] who found $\mathrm{NH}_{3}$ bonds to HKUST-1 stronger than $\mathrm{NO}_{x}$ by DFT calculations.

\subsection{Analysis of Electronic Properties}

Adsorption of NCCs on M-HKUST-1 is associated with charge transfer between the MOFs and the adsorbate. To understand the nature of chemical bonding between NCCs and the M-HKUST-1 substrate, we perform the Bader charges [46] analysis, partitioning a charge density grid into Bader volumes scaled linearly with the number of grid points on individual atoms. Table 4 provides the net NCC charge upon adsorption.

As shown in Table 4, $\mathrm{NO}_{\mathrm{x}}(\mathrm{x}=1,2)$ adsorption results, for almost all M-HKUST-1, in a negatively charged adsorbate species indicating adsorbates accepts electrons from the MOFs while the opposite trend is found for $\mathrm{NH}_{3}$ adsorption where $\mathrm{NH}_{3}$ is positively charged suggesting the electrons transfers from $\mathrm{NH}_{3}$ to the MOFs. The negative charging indicates the number of back-donated electrons to the antibonding orbitals of the $\mathrm{NO}_{\mathrm{x}}(\mathrm{x}=1,2)$ adsorbates is larger than that of denoted electrons from adsorbates to the MOFs. This results in the weaker interatomic bonds and increased interatomic 
distances $d_{\mathrm{N}-\mathrm{O}}$ (Table 1 ). The similar result is observed for $\mathrm{NO}$ adsorption on $\beta-\mathrm{Mo}_{2} \mathrm{C}$ in our previous work [42]. We found NO are negatively charged on the $\beta-\mathrm{Mo}_{2} \mathrm{C}(0001)$ surface [42], while the $\mathrm{NH}_{3}$ molecule, as a typical Lewis base with a lone pair of electrons, prefers to denote elections to the substrate during the adsorption. We also found that the charge values of adsorbed $\mathrm{NO}_{2}$ are larger than those of adsorbed $\mathrm{NO}$ and $\mathrm{NH}_{3}$ in absolute size indicating a larger charge transfer between $\mathrm{NO}_{2}$ and MOFs than the other two systems.

Table 4. Bader charge $\mathrm{q}_{\mathrm{x}}\left(\mathrm{x}=\mathrm{NO}, \mathrm{NO}_{2}-\mathrm{t} 1, \mathrm{NO}_{2}-\mathrm{t} 2, \mathrm{NO}_{2}-\mathrm{b} 1, \mathrm{NO}_{2}-\mathrm{b} 2\right.$, and $\left.\mathrm{NH}_{3}\right)$ for $\mathrm{NCCs}$ on M-HKUST-1 (The charges are shown for the entire NCCs molecule).

\begin{tabular}{|c|c|c|c|c|c|c|}
\hline Metal & $\mathrm{q}_{\mathrm{NO}}$ & qNO2-t1 & $\mathrm{qNO}_{\mathrm{N}-\mathrm{t} 2}$ & $\mathrm{q}_{\mathrm{NO} 2-\mathrm{b} 1}$ & $\mathrm{q}_{\mathrm{NO} 2-\mathrm{b} 2}$ & $\mathrm{q}_{\mathrm{NH} 3}$ \\
\hline $\mathrm{Be}$ & 0.01 & 0.00 & -0.20 & - & - & 0.11 \\
\hline $\mathrm{Fe}$ & -0.10 & -0.45 & -0.55 & - & - & 0.19 \\
\hline $\mathrm{Ni}$ & -0.15 & -0.26 & -0.38 & - & - & 0.17 \\
\hline $\mathrm{Cr}$ & -0.28 & - & -0.27 & - & -0.40 & 0.08 \\
\hline Co & -0.19 & -0.37 & -0.45 & - & - & 0.19 \\
\hline $\mathrm{Cu}$ & 0.04 & -0.17 & -0.09 & - & - & 0.11 \\
\hline V & -0.45 & -0.49 & -0.58 & - & -0.53 & 0.14 \\
\hline $\mathrm{Zn}$ & 0.04 & -0.05 & -0.15 & - & - & 0.18 \\
\hline Mo & -0.19 & -0.42 & -0.44 & - & - & 0.03 \\
\hline Mn & -0.33 & -0.51 & -0.57 & - & - & 0.13 \\
\hline $\mathrm{W}$ & -0.19 & -0.56 & -0.60 & - & - & 0.04 \\
\hline Sn & -0.01 & -0.08 & -0.01 & -0.29 & - & 0.00 \\
\hline $\mathrm{Ti}$ & -0.65 & - & - & -0.72 & -0.72 & 0.07 \\
\hline $\mathrm{Cd}$ & -0.01 & -0.10 & -0.07 & - & - & 0.16 \\
\hline $\mathrm{Mg}$ & -0.04 & -0.32 & -0.16 & - & - & 0.06 \\
\hline Sc & -0.65 & - & -0.75 & -0.77 & -0.73 & 0.08 \\
\hline $\mathrm{Ca}$ & -0.09 & - & -0.31 & -0.44 & - & 0.06 \\
\hline $\mathrm{Sr}$ & -0.19 & - & -0.48 & -0.57 & - & 0.04 \\
\hline $\mathrm{Ba}$ & -0.22 & -0.52 & -0.52 & -0.57 & - & 0.02 \\
\hline
\end{tabular}

We then examined the distribution of charge for NCC molecular adsorption on M-HKUST-1 $(\mathrm{M}=\mathrm{Cu}, \mathrm{Ti}, \mathrm{Sc}$, and $\mathrm{Be})$ using electron density difference maps. The electron density difference $(\Delta \rho)$ was calculated according to our previous work [47]. The charge density maps are also provided in Figure S5 for comparison; note that non-covalent interaction plots [48] may provide extra information about the inter and intramolecular non-covalent interactions (i.e., hydrogen bonds, steric clashes and van der Waals) in systems, while the electronic analysis based on the Bader charge analysis and electron density difference maps in this work can provide enough data regarding the nature of the chemical bonding. As shown in Figure 5, some metal orbitals are found to be depleted upon adsorption on MOFs associated with the charge redistribution of the $\mathrm{M}-\mathrm{O}$ bond in the SBUs and new formed M-N/O bond. When the electron density of the $\mathrm{M}-\mathrm{O}$ bond in the SBUs decreased, the electron density along the $\mathrm{M}-\mathrm{N} / \mathrm{O}$ bond increased. Compared with the original $\mathrm{Cu}-\mathrm{HKUST}-1$, the change of the electron density of the $\mathrm{M}-\mathrm{N}$ bond is larger for M-HKUST-1 $(\mathrm{M}=\mathrm{Ti}, \mathrm{Sc}$, and $\mathrm{Be})$.

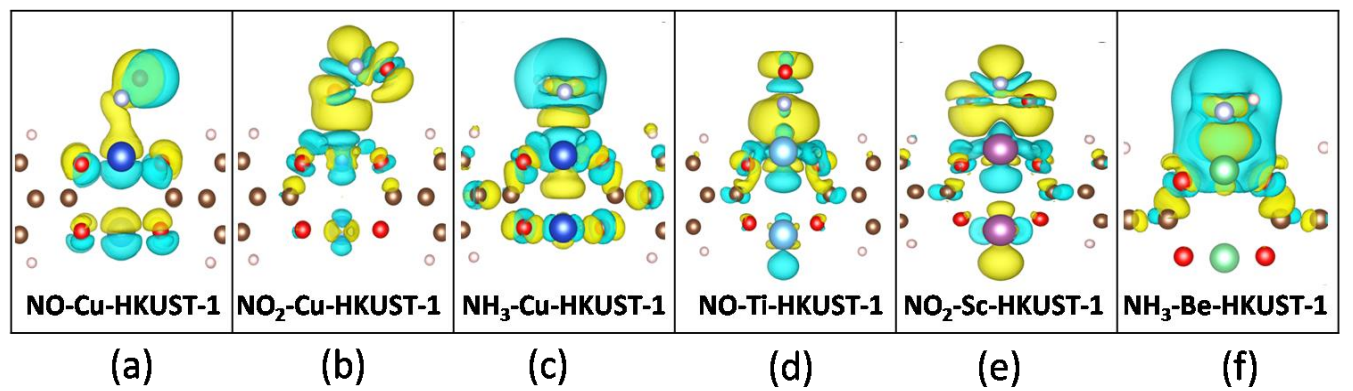

Figure 5. Selected electron density difference map for NCC molecules adsorbed on M-HKUST-1: (a) NO on Cu-HKUST-1, (b) $\mathrm{NO}_{2}$ on Cu-HKUST-1, (c) $\mathrm{NH}_{3}$ on Cu-HKUST-1, (d) NO on Ti-HKUST-1, (e) $\mathrm{NO}_{2}$ on Sc-HKUST-1, and (f) $\mathrm{NH}_{3}$ on Be-HKUST-1. For each case, only the most stable adsorption configuration is considered. Accumulation region in yellow and depletion regions in blue. 


\subsection{Correlations}

\subsubsection{Adsorption Energy and Bader Charge}

The correlation between the adsorption energy and the Bader charge of the adsorbed molecules, the metal atomic radius, and the forming $\mathrm{M}-\mathrm{N}$ band distance is provided in Figure 6.

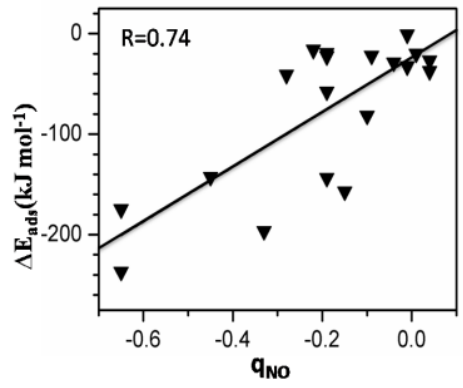

(a)

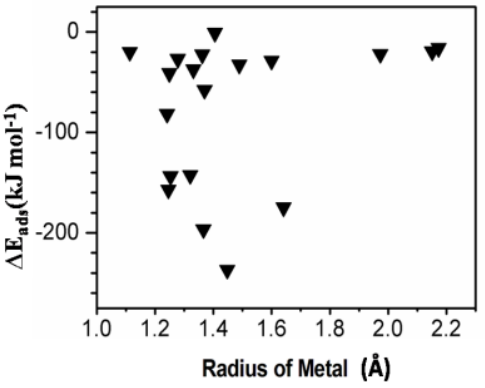

(b)

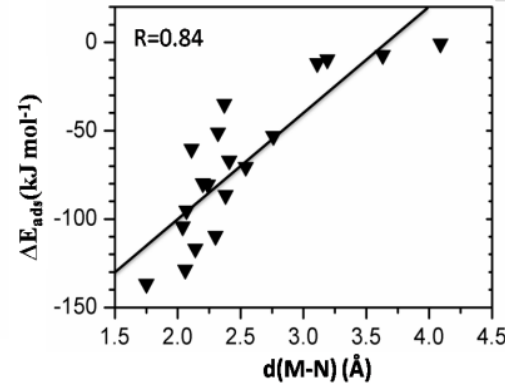

(c)

Figure 6. The calculated relationship between the (a) NO adsorption energy on M-HKUST-1 and total Bader charge on adsorbed $\mathrm{NO}$, (b) $\mathrm{NO}$ adsorption energy and metal atomic radius, and (c) $\mathrm{NH}_{3}$ adsorption energy and $\mathrm{M}-\mathrm{N}$ bond distance.

In general, the adsorption energy is linearly related to the total Bader charge of the adsorbed molecule since the electrostatic interaction is an important part of the interaction between the MOFs and the NCCs molecules. We take the $\mathrm{NO}_{2}$ adsorption on M-HKUST-1 as an example. As shown in Figure $6 \mathrm{a}$, the most charged compounds in the adsorbed molecules exhibited the largest adsorption energy. $\mathrm{NO}_{2}$ adsorption on Sc-HKUST-1 via the b1 mode with the largest adsorption energy yields the largest Bader charge of -0.77 among all the adsorbed $\mathrm{NO}_{2}$ species. Similarly, the adsorbed $\mathrm{NO}$ on Ti-HKUST-1 presents the largest Bader charge of -0.65 resulting in the strongest adsorption.

\subsubsection{Adsorption Energy and Metal Radius}

Figure $6 \mathrm{~b}$ depicts the relationship between the adsorption energy and the atomic radius of the substituted metal atom. Generally, the smaller the metal atom, the stronger the polarization effect, and the stronger polarization effect will induce a stronger binding between the adsorbates and MOFs. Our results show that no clear dependence between the adsorption energy and the metal atomic radii was observed in these compounds. This behavior can be understood. Besides the polarization effect, the substitution by the metal atom with different atomic radius also has the size effect, which will affect the structure of the SBU. A case in point is NCC molecular adsorption on Be-HKUST-1. As an element with the smallest atomic radius in our studies, it is expected that Be has the strongest polarization effect on NCC molecules, resulting in the largest $\Delta \mathrm{E}_{\mathrm{ads}}$. It is only true for $\mathrm{NH}_{3}$ adsorption where Be-HKUST- 1 yields the largest $\Delta \mathrm{E}_{\text {ads }}$ towards $\mathrm{NH}_{3}$ adsorption; for $\mathrm{NO}$ and $\mathrm{NO}_{2}$ adsorption, this is not the case. The actual adsorption energy for $\mathrm{NO}_{2}$ (NO) adsorption is only $-2.9(-20.0) \mathrm{kJ} \mathrm{mol}^{-1}$, which is 38 (6.8) $\mathrm{kJ} \mathrm{mol}^{-1}$ higher than that of Cu-HKUST-1. This can be attributed to the size/structural effect within the SBU. With the smaller radius, when Be employs the same coordination pattern as the Cu-HKUST-1 prototype, it will induce a strong contraction of the MOFs structure, especially within the SBU with the much shorter $\mathrm{d}(\mathrm{M}-\mathrm{O})$ of $1.74 \AA$. As a result, the most stable adsorption configuration is unpredictable. For $\mathrm{NO}_{2}$ adsorption, the energetically favorable structure shifts from the $\mathrm{t} 1$ with the central $\mathrm{N}$ atom binding to the metal center to $\mathrm{t} 2$ with the oxygen end binding to the metal center. In general, the relationship between the NCCs adsorption energy and the metal radius is complicated by changes in the structure of the MOFs due to the size/structural effects. The same phenomenon has been observed for $\mathrm{CO}_{2}$ adsorption HKUST-1 by Hyun et al. [36]. 


\subsubsection{Adsorption Energy and $\mathrm{M}-\mathrm{N}(\mathrm{O})$ Bond Distance}

Interestingly, we found a linear relationship between the adsorption energy and the forming M-N band distance for $\mathrm{NH}_{3} @$ M-HKUST-1 (Figure 6c), while, for the other systems, there is a clear suggestion that the linear relationship is broken by the low-symmetry of adsorbed structure upon the adsorption of $\mathrm{NO}$ and $\mathrm{NO}_{2}$ on MOFs. For example, the formed $\mathrm{M}-\mathrm{N}-\mathrm{O}$ angle towards $\mathrm{NO}$ adsorption on M-HKUST-1 divided into three groups generally: $\sim 180^{\circ}, \sim 125^{\circ}$, and $\sim 155^{\circ}$ suggesting strongly the broken symmetry of M-HKUST-1 and inducing a low symmetry of the adsorbed states. Therefore, this linear model has limitations and should be carefully used to explain adsorption trends of adsorbates on MOFs.

\section{Conclusions}

Metal-organic frameworks show great potential for toxic gas capture applications due to their high adsorption capacities and structural flexibility. Among them, metal-substituted M-HKUST-1 exhibits very high NCC uptake at low pressures due to its gravimetric density of under-coordinated "open-metal" sites. To identify promising candidates with better ADN performance than those currently known ones, we use first principle calculations to screen 19 metal-substituted compounds M-HKUST-1 (M = Be, Fe, Ni, Cr, Co, Cu, V, Zn, Mo, Mn, W, Sn, Ti, Cd, Mg, Sc, Ca, Sr, and Ba) towards their NCC adsorption behavior.

Our calculations show that among 19 screened M-HKUST-1, four M-HKUST-1 variants $(\mathrm{M}=\mathrm{Ni}$, $\mathrm{Co}, \mathrm{V}$, and $\mathrm{Sc}$ ) with excellent adsorption properties for three nitrogen-containing compounds $\left(\mathrm{NO}_{1} \mathrm{NO}_{2}\right.$, and $\mathrm{NH}_{3}$ ) were screened out. Their adsorption capacities for three nitrogen-containing compounds are expected to exceed their original structure (Cu-HKUST-1). Considering a specific adsorption target separately, Ti-HKUST-1 shows the best adsorption performance for $\mathrm{NO}$ with the largest adsorption energy of $-236.9 \mathrm{~kJ} \mathrm{~mol}^{-1}$. For $\mathrm{NO}_{2}$ adsorption, Ti-HKUST-1 also shows an excellent performance, but Sc-HKUST-1 is even better. Sc-HKUST-1 is found to yield the strongest interaction between $\mathrm{NO}_{2}$ molecule and MOFs with $\Delta \mathrm{E}_{\mathrm{ads}}$ of $-303.6 \mathrm{~kJ} \mathrm{~mol}^{-1}$. For $\mathrm{NH}_{3}$ adsorption, Be-HKUST-1 yields the largest $\mathrm{NH}_{3}$ adsorption energy of $-136.7 \mathrm{~kJ} \mathrm{~mol}^{-1}$, which is $56.9 \mathrm{~kJ} \mathrm{~mol}^{-1} \mathrm{~L}$ larger than Cu-HKUST-1, suggesting the best $\mathrm{NH}_{3}$ adsorption behavior.

The dissociative adsorption for all NCCs is much less favorable compared with molecular adsorption thermodynamically. There is only one exception. $\mathrm{NO}_{2}$ adsorption on V-HKUST-1 prefers to dissociate into $\mathrm{NO}$ and $\mathrm{O}$ thermodynamically. A further calculation for $\mathrm{NH}_{3}$ dissociation on the original Cu-HKUST-1 connecting the energetically most stable co-adsorption geometries yields a reaction barrier as high as $458.2 \mathrm{~kJ} \mathrm{~mol}^{-1}$, which is consistent with the experimental observation that upon $\mathrm{NH}_{3}$ adsorption on $\mathrm{Cu}-\mathrm{HKUST}-1$, no adsorbed $\mathrm{NH}_{3}$ undergoes decomposition.

The bulk calculations show that extremely small or large ions will distort the structure of HKUST-1, causing structural effects. As a result, the adsorption energy of NCCs on M-HKUST-1 is not related to the ionic radii of the substituted metals. The lateral electronic analysis found a linear relationship between the total Bader charge of the adsorbed NCC molecules and adsorption energy. These results indicated the adsorption of NCCs on M-HKUST-1 mainly relies on the electronic structure instead to depend on the structural/size features of the MOFs. However, a simple model of net charge transfer cannot be employed to all of the NCCs species in this work. NO and $\mathrm{NO}_{2}$ on M-HKUST-1 are negatively charged, while the absorbed $\mathrm{NH}_{3}$ is positive. Despite the fact that the isostructural substitution of $\mathrm{Cu}$ to the other metals is a major simplification of the system that represents the ideal situation, and the synthesized structure in experiments may be much more complex, the present studies may shed light on searching for better adsorbants of ADN for the MOF community.

Supplementary Materials: The following are available online at http:/ /www.mdpi.com/2079-4991/8/11/958/s1, Figure S1: (a) HKUST-1 bulk structure containing unsaturated metal sites, (b) bulk structures used in this work, (c) the structure of secondary building unit (SBU), (d) three pores in inactivated HKUST-1, (e) the side view with the similar angle of our used structure $b$, ( $f$ ) the zoomed pore which will be occupied by the adsorbed NCCs molecules. Figures S2-S4: Adsorption configuration for $\mathrm{NO}, \mathrm{NH}_{3}$ and $\mathrm{NO}_{2}$ molecular adsorption on M-HKUST-1. 
Figure S5: The 3D (top) and 2D (bottom) charge density map measured in e/ $\mathrm{A} 3$ for (a) $\mathrm{NO}$, (b) $\mathrm{NO}_{2}$, and (c) $\mathrm{NH}_{3}$ adsorption on Cu-HKUST-1. Table S1: Calculated bulk lattice parameters, metal-oxygen bond length d(M-O) $(\AA)$, metal-metal distance $\mathrm{d}(\mathrm{M}-\mathrm{M})(\AA)$, a distance between metal and the basal plane of four $\mathrm{O}$ atoms $\mathrm{d}(\mathrm{M}-4 \mathrm{O})$ $(\AA)$ of M-HKUST-1, dihedral angle $\Delta\left(^{\circ}\right)$ formed by one metal center and its three bonded oxygen atoms in SBU, deformation degree (\%) and distance between metal atoms M2 and M3 d(M2-M3) ( $\AA$ ) shown in Figure S1. Table S2: The bond distance and bond angle of $\mathrm{NO}_{2}$ in the adsorption state.

Author Contributions: DFT simulations, S.Z.; data analysis, Y.Z., N.L., P.M., J.W. and X.-R.S.; writing-original draft preparation, S.Z.; writing—review and editing, X.-R.S.; supervision, X.-R.S.

Funding: This research was funded by the Shanghai Pujiang Program, grant number 17PJ1403100, the National Natural Science Foundation of China, grant number 21703137, Shanghai University Young Teachers Training Foundation, grant number ZZGCD16024 and Startup Foundation for Doctors of Shanghai University of Engineering Science, grant number 2017-09.

Acknowledgments: This research was supported by the Shanghai Pujiang Program (grant no. 17PJ1403100), the National Natural Science Foundation of China (grant no. 21703137), Shanghai University Young Teachers Training Foundation (grant no. ZZGCD16024) and Startup Foundation for Doctors of Shanghai University of Engineering Science (grant no. 2017-09).

Conflicts of Interest: The authors declare no conflict of interest.

\section{References}

1. Tan, K.; Zuluaga, S.; Wang, H.; Canepa, P.; Soliman, K.; Cure, J.; Li, J.; Thonhauser, T.; Chabal, Y.J. Interaction of Acid Gases $\mathrm{SO}_{2}$ and $\mathrm{NO}_{2}$ with Coordinatively Unsaturated Metal Organic Frameworks: M-MOF-74 ( $\mathrm{M}=\mathrm{Zn}, \mathrm{Mg}, \mathrm{Ni}, \mathrm{Co})$. Chem. Mater. 2017, 29, 4227-4235. [CrossRef]

2. Khan, N.A.; Hasan, Z.; Jhung, S.H. Adsorptive removal of hazardous materials using metal-organic frameworks (MOFs): A review. J. Hazard. Mater. 2013, 244, 444-456. [CrossRef] [PubMed]

3. Hinks, N.J.; McKinlay, A.C.; Xiao, B.; Wheatley, P.S.; Morris, R.E. Metal organic frameworks as NO delivery materials for biological applications. Microporous Mesoporous Mater. 2010, 129, 330-334. [CrossRef]

4. Bowser, B.; Brower, L.; Ohnsorg, M.; Gentry, L.; Beaudoin, C.; Anderson, M.; Bowser, B.H.; Brower, L.J.; Ohnsorg, M.L.; Gentry, L.K.; et al. Comparison of Surface-Bound and Free-Standing Variations of HKUST-1 MOFs: Effect of Activation and Ammonia Exposure on Morphology, Crystallinity, and Composition. Nanomaterials 2018, 8, 650. [CrossRef] [PubMed]

5. Yepez, R.; García, S.; Schachat, P.; Sánchez-Sánchez, M.; González-Estefan, J.H.; González-Zamora, E.; Ibarra, I.A.; Aguilar-Pliego, J. Catalytic activity of HKUST-1 in the oxidation of trans-ferulic acid to vanillin. New J. Chem. 2015, 39, 5112-5115. [CrossRef]

6. Campbell, J.; Székely, G.; Davies, R.P.; Braddock, D.C.; Livingston, A.G. Fabrication of hybrid polymer/metal organic framework membranes: Mixed matrix membranes versus in situ growth. J. Mater. Chem. A 2014, 2, 9260-9271. [CrossRef]

7. Campbell, J.; Burgal, J.D.S.; Szekely, G.; Davies, R.P.; Braddock, D.C.; Livingston, A. Hybrid polymer/MOF membranes for Organic Solvent Nanofiltration (OSN): Chemical modification and the quest for perfection. J. Membr. Sci. 2016, 503, 166-176. [CrossRef]

8. Mosleh, S.; Rahimi, M.R.; Ghaedi, M.; Dashtian, K. HKUST-1-MOF-BiVO 4 hybrid as a new sonophotocatalyst for simultaneous degradation of disulfine blue and rose bengal dyes: Optimization and statistical modelling. RSC Adv. 2016, 6, 61516-61527. [CrossRef]

9. Razali, M.; Kim, J.F.; Attfield, M.; Budd, P.M.; Drioli, E.; Lee, Y.M.; Szekely, G. Sustainable wastewater treatment and recycling in membrane manufacturing. Green Chem. 2015, 17, 5196-5205. [CrossRef]

10. Álvarez, J.R.; Sánchez-González, E.; Pérez, E.; Schneider-Revueltas, E.; Martínez, A.; Tejeda-Cruz, A.; Islas-Jácome, A.; González-Zamora, E.; Ibarra, I.A. Structure stability of HKUST-1 towards water and ethanol and their effect on its $\mathrm{CO}_{2}$ capture properties. Dalton Trans. 2017, 46, 9192-9200. [CrossRef] [PubMed]

11. Supronowicz, B.; Mavrandonakis, A.; Heine, T. Interaction of Biologically Important Organic Molecules with the Unsaturated Copper Centers of the HKUST-1 Metal-Organic Framework: An Ab-Initio Study. J. Phys. Chem. C 2015, 119, 3024-3032. [CrossRef]

12. Khan, N.A.; Jhung, S.H. Adsorptive removal and separation of chemicals with metal-organic frameworks: Contribution of $\pi$-complexation. J. Hazard. Mater. 2017, 325, 198-213. [CrossRef] [PubMed] 
13. Xiao, B.; Wheatley, P.S.; Zhao, X.; Fletcher, A.J.; Fox, S.; Rossi, A.G.; Megson, I.L.; Bordiga, S.; Regli, L.; Thomas, K.M.; et al. High-Capacity Hydrogen and Nitric Oxide Adsorption and Storage in a Metal-Organic Framework. J. Am. Chem. Soc. 2007, 129, 1203-1209. [CrossRef] [PubMed]

14. Levasseur, B.; Petit, C.; Bandosz, T.J. Reactive Adsorption of $\mathrm{NO}_{2}$ on Copper-Based Metal-Organic Framework and Graphite Oxide/Metal-Organic Framework Composites. ACS Appl. Mater. Interfaces 2010, 2, 3606-3613. [CrossRef] [PubMed]

15. Borfecchia, E.; Maurelli, S.; Gianolio, D.; Groppo, E.; Chiesa, M.; Bonino, F.; Lamberti, C. Insights into Adsorption of $\mathrm{NH}_{3}$ on HKUST-1 Metal-Organic Framework: A Multitechnique Approach. J. Phys. Chem. C 2012, 116, 19839-19850. [CrossRef]

16. Murray, L.J.; Dinca, M.; Yano, J.; Chavan, S.; Bordiga, S.; Brown, C.M.; Long, J.R. Highly-Selective and Reversible $\mathrm{O}_{2}$ Binding in $\mathrm{Cr}_{3}\left(1,3,5\right.$-benzenetricarboxylate) ${ }_{2}$. J. Am. Chem. Soc. 2010, 132, 7856-7857. [CrossRef] [PubMed]

17. Maniam, P.; Stock, N.; Chemie, A.; Kiel, D. Investigation of Porous Ni-Based Metal À Organic Frameworks Containing Paddle-Wheel Type Inorganic Building Units via High-Throughput Methods. Inorg. Chem. 2011, 50, 5085-5097. [CrossRef] [PubMed]

18. Feldblyum, J.I.; Liu, M.; Gidley, D.W.; Matzger, A.J. Reconciling the Discrepancies between Crystallographic Porosity and Guest Access as Exemplified by Zn-HKUST-1. J. Am. Chem. Soc. 2011, 133, 18257-18263. [CrossRef] [PubMed]

19. Kramer, M.; Schwarz, U.; Kaskel, S. Synthesis and properties of the metal-organic framework $\mathrm{Mo}_{3}(\mathrm{BTC})_{2}$. J. Mater. Chem. 2006, 16, 2245-2248. [CrossRef]

20. Howe, J.D.; Liu, Y.; Flores, L.; Dixon, D.A.; Sholl, D.S. Acid Gas Adsorption on Metal-Organic Framework Nanosheets as a Model of an "All-Surface" Material. J. Chem. Theory Comput. 2017, 13, 1341-1350. [CrossRef] [PubMed]

21. Sun, L.; Yang, L.; Zhang, Y.; Shi, Q.; Lu, R.; Deng, W. Accurate van der Waals Force Field for Gas Adsorption in Porous Materials. J. Comput. Chem. 2017, 38, 1991-1999. [CrossRef] [PubMed]

22. Ongari, D.; Tiana, D.; Stoneburner, S.J.; Gagliardi, L.; Smit, B. Origin of the Strong Interaction between Polar Molecules and Copper(II) Paddle-Wheels in Metal Organic Frameworks. J. Phys. Chem. C 2017, 121, 15135-15144. [CrossRef] [PubMed]

23. Chen, Z.; Ling, L.; Wang, B.; Fan, H.; Shangguan, J.; Mi, J. Adsorptive desulfurization with metal-organic frameworks: A density functional theory investigation. Appl. Surf. Sci. 2016, 387, 483-490. [CrossRef]

24. Tan, K.; Zuluaga, S.; Gong, Q.; Gao, Y.; Nijem, N.; Li, J.; Thonhauser, T.; Chabal, Y.J. Competitive Coadsorption of $\mathrm{CO}_{2}$ with $\mathrm{H}_{2} \mathrm{O}, \mathrm{NH}_{3}, \mathrm{SO}_{2}, \mathrm{NO}, \mathrm{NO}_{2}, \mathrm{~N}_{2}, \mathrm{O}_{2}$, and $\mathrm{CH}_{4}$ in M-MOF-74 (M= Mg, Co, Ni): The Role of Hydrogen Bonding. Chem. Mater. 2015, 27, 2203-2217. [CrossRef]

25. Liu, Y.; Guo, F.; Hu, J.; Zhao, S.; Liu, H.; Hu, Y. Screening of desulfurization adsorbent in metal-organic frameworks: A classical density functional approach. Chem. Eng. Sci. 2015, 137, 170-177. [CrossRef]

26. Koh, H.S.; Rana, M.K.; Wong-Foy, A.G.; Siegel, D.J. Predicting Methane Storage in Open-Metal-Site Metal-Organic Frameworks. J. Phys. Chem. C 2015, 119, 13451-13458. [CrossRef]

27. Fang, H.; Awati, R.; Boulfelfel, S.E.; Ravikovitch, P.I.; Sholl, D.S. First-Principles-Derived Force Fields for $\mathrm{CH}_{4}$ Adsorption and Diffusion in Siliceous Zeolites. J. Phys. Chem. C 2018, 122, 12880-12891. [CrossRef]

28. Ketrat, S.; Maihom, T.; Wannakao, S.; Probst, M.; Nokbin, S.; Limtrakul, J. Coordinatively Unsaturated Metal-Organic Frameworks $\mathrm{M}_{3}(\mathrm{btc})_{2}(\mathrm{M}=\mathrm{Cr}, \mathrm{Fe}, \mathrm{Co}, \mathrm{Ni}, \mathrm{Cu}$, and $\mathrm{Zn})$ Catalyzing the Oxidation of $\mathrm{CO}$ by $\mathrm{N}_{2} \mathrm{O}$ : Insight from DFT Calculations. Inorg. Chem. 2017, 56, 14005-14012. [CrossRef] [PubMed]

29. Demir, H.; Greathouse, J.A.; Staiger, C.L.; Perry, J.J.; Allendorf, M.D.; Sholl, D.S. DFT-based force field development for noble gas adsorption in metal organic frameworks. J. Mater. Chem. A 2015, 3, 23539-23548. [CrossRef]

30. Gu, Z.-G.; Heinke, L.; Wöll, C.; Neumann, T.; Wenzel, W.; Li, Q.; Fink, K.; Gordan, O.D.; Zahn, D.R.T. Experimental and theoretical investigations of the electronic band structure of metal-organic frameworks of HKUST-1 type. Appl. Phys. Lett. 2015, 107, 183301. [CrossRef]

31. Kang, M.; Luo, D.; Lin, Z.; Thiele, G.; Dehnen, S. Crystalline beryllium carboxylate frameworks containing inorganic chains of $\mathrm{BeO}_{4}$ tetrahedra. CrystEngComm 2013, 15, 1845. [CrossRef]

32. Kresse, G.; Furthmüller, J. Efficiency of ab-initio total energy calculations for metals and semiconductors using a plane-wave basis set. Comput. Mater. Sci. 1996, 6, 15-50. [CrossRef] 
33. Kresse, G.; Furthmüller, J. Efficient iterative schemes for ab-initio total-energy calculations using a plane-wave basis set. Phys. Rev. B 1996, 54, 11169-11186. [CrossRef]

34. Kresse, G.; Joubert, D. From ultrasoft pseudopotentials to the projector augmented-wave method. Phys. Rev. B Condens. Matter Mater. Phys. 1999, 59, 1758-1775. [CrossRef]

35. Perdew, J.P.; Burke, K.; Ernzerhof, M. Generalized Gradient Approximation Made Simple. Phys. Rev. Lett. 1996, 77, 3865-3868. [CrossRef] [PubMed]

36. Koh, H.S.; Rana, M.K.; Hwang, J.; Siegel, D.J. Thermodynamic screening of metal-substituted MOFs for carbon capture. Phys. Chem. Chem. Phys. 2013, 15, 4573-4581. [CrossRef] [PubMed]

37. Supronowicz, B.; Mavrandonakis, A.; Heine, T. Interaction of Small Gases with the Unsaturated Metal Centers of the HKUST-1 Metal Organic Framework. J. Phys. Chem. C 2013, 117, 14570-14578. [CrossRef]

38. Nie, X.; Kulkarni, A.; Sholl, D.S. Computational Prediction of Metal Organic Frameworks Suitable for Molecular Infiltration as a Route to Development of Conductive Materials. J. Phys. Chem. Lett. 2015, 6, 1586-1591. [CrossRef] [PubMed]

39. Sholl, D.S.; Steckel, J.A. Density Functional Theory: A Practical Introduction; Wiley: Hoboken, NJ, USA, 2009.

40. Henkelman, G.; Jónsson, H. Improved tangent estimate in the nudged elastic band method for finding minimum energy paths and saddle points. J. Chem. Phys. 2000, 113, 9978-9985. [CrossRef]

41. Henkelman, G.; Jónsson, H. A dimer method for finding saddle points on high dimensional potential surfaces using only first derivatives. J. Chem. Phys. 1999, 111, 7010-7022. [CrossRef]

42. Shi, X.R.; Wang, J.G.; Hermann, K. CO and NO Adsorption and Dissociation at the $\beta-\mathrm{Mo}_{2} \mathrm{C}(0001)$ Surface: A Density Functional Theory Study. J. Phys. Chem. C 2010, 114, 13630-13641. [CrossRef]

43. Shi, X.-R.; Wang, S.-G.; Wang, J. Chemisorption of oxygen and subsequent reactions on low index surfaces of ß-Mo2C: Insights from first-principles thermodynamics and kinetics. J. Mol. Catal. A Chem. 2016, 417, $53-63$. [CrossRef]

44. Khan, A.H.; Peikert, K.; Fröba, M.; Bertmer, M. NO adsorption in amino-modified $\mathrm{Cu}_{3}(\mathrm{btc})_{2}$-type MOFs studied by solid-state NMR. Microporous Mesoporous Mater. 2015, 216, 111-117. [CrossRef]

45. Petit, C.; Levasseur, B.; Mendoza, B.; Bandosz, T.J. Reactive adsorption of acidic gases on MOF/graphite oxide composites. Microporous Mesoporous Mater. 2012, 154, 107-112. [CrossRef]

46. Tang, W.; Sanville, E.; Henkelman, G. A grid-based Bader analysis algorithm without lattice bias. J. Phys. Condens. Matter 2009, 21, 084204. [CrossRef] [PubMed]

47. Shi, X.-R.; Sholl, D.S. Nucleation of $\mathrm{Rh}_{\mathrm{n}}(\mathrm{n}=1-5)$ Clusters on $\gamma-\mathrm{Al}_{2} \mathrm{O}_{3}$ Surfaces: A Density Functional Theory Study. J. Phys. Chem. C 2012, 116, 10623-10631. [CrossRef]

48. Otero-de-la-Roza, A.; Johnson, E.R.; Contreras-García, J. Revealing non-covalent interactions in solids: NCI plots revisited. Phys. Chem. Chem. Phys. 2012, 14, 12165. [CrossRef] [PubMed] 